\title{
ET SCRIBATUR VIRO NOBILI SER ANGELO VENERIO, CONSUli NOSTRO Sibilie. ACCiÓn CONSUlar, COMUNICACIÓN DIPLOMÁTICA Y ESTRATEGIA MERCANTIL VENECIANA EN CASTILLA A PRINCIPIOS DEL SIGLO XV
}

\author{
Raúl GonzÁlez Arévalo \\ Universidad de Granada ${ }^{1}$ \\ TOMmaso VIDAL \\ Università degli Studi di Padova ${ }^{2}$
}

Recibido: 20 de enero de 2021

Aceptado: 24 de abril de 2021

\begin{abstract}
Resumen
El presente artículo propone la edición y estudio de la única carta enviada por un cónsul veneciano en Castilla que se ha localizado hasta el momento. Se reconstruye la trayectoria vital de su autor, Angelo Venier, y la de Luca Falier, mercader veneciano con intereses en Andalucía, nombrado en la carta. La riqueza del contenido permite abordar temas tan dispares y complejos como el alcance de la navegación privada veneciana en la península ibérica; los mecanismos jurídicos para la resolución de conflictos entre naciones extranjeras en Castilla; la situación de los genoveses; las perspectivas venecianas en Andalucía, y asuntos mercantiles y privados de otros venecianos presentes en Sevilla. Emerge una imagen mucho más detallada de lo conocido hasta el momento.
\end{abstract}

\section{Palabras clave}

Venecia, Castilla, diplomacia, comercio, navegación privada

\begin{abstract}
The present article proposes the edition and study of the only letter sent by a Venetian consul in Castile found until now. We reconstruct the life course of its author, Angelo Venier, and Luca Falier's, a Venetian merchant with interests in Andalusia, named in the letter. The richness of contents allows us to deal with many different and complex issues, such as Venetian private navigation in the Iberian

1 Departamento de Historia Medieval y CC y TT HH, Facultad de Filosofía y Letras, Campus de La Cartuja, 18071, Granada. Correo electrónico: rgonzalezarevalo@ugr.es. OrCID: https://orcid.org/ 00000002-4204-0495

2 Dipartimento di Scienze Storiche, Georgrafiche e dell'Antichità, Via del Vescovado 30, 35141, Padova PD, Italia. Correo electrónico: vidal.tommaso@gmail.com. ORCID: https://orcid.org/0000-0002-8019-9077
\end{abstract}


peninsula; juridical mechanisms for the resolution of conflicts between foreign merchant nations in Castile; the Genoese situation; Venetian perspectives in Andalusia; and merchant and private businesses of other Venetians in Seville. The image that arises is much more detailed than what we knew up to this moment.

\section{Keywords}

Venice, Castille, diplomacy, commerce, private navigation

\section{Riassunto}

Il presente articolo propone l'edizione e lo studio dell'unica lettera di un console veneziano in Castiglia trovata finora. Si ricostruisce il percorso di vita dell'autore, Angelo Venier, e di Luca Falier, mercante veneziano con interessi in Andalusia, nominato nella lettera. La ricchezza di informazioni permette affrontare argomenti talmente diversi e complessi come la navigazione privata veneziana nella penisola iberica; i meccanismi giuridici per la risoluzione di conflitti tra nazioni mercantili straniere in Castiglia; la situazione dei Genovesi; le prospettive veneziani in Andalusia, così come affari mercantili e privati di veneziani presenti in Siviglia. L'immago che emerge è molto più dettagliata di quanto si conosceva prima.

\section{Parole chiave}

Venezia, Castiglia, diplomazia, commercio, navigazione privata

\section{Los orígenes del consulado veneciano de Sevilla: embajadas y privilegios en el siglo $\mathrm{XIV}^{3}$}

Las investigaciones sobre la presencia veneciana en Andalucía ocupan un lugar muy reducido en la historiografía sobre los italianos en Castilla. ${ }^{4}$ Bien es cierto que, más allá de la llegada anual de las mude, los famosos convoyes de galeras mercantiles, ${ }^{5}$ las informaciones sobre el arraigo y la promoción social de mercaderes de la Serenísima en el territorio son realmente escasas. ${ }^{6}$ La explicación reside en una medida muy importante en que, hasta no hace mucho, para abordar las relaciones entre Castilla y Venecia se han empleado preferentemente las fuentes castellanas y una óptica iberocéntrica.

\footnotetext{
3 Este trabajo es el resultado de la participación de sus autores como mentor (González Arévalo) y mentee (Vidal) en el Arqus Online Mentoring Programme, iniciativa de ARQUS, European University Alliance de la Unión Europea. Asimismo, forma parte del Proyecto I+D «Las ciudades de la Corona de Castilla. Dinámicas y proyección de los sistemas urbanos entre 1300 y 1600» (HAR2017-82983-P), financiado por el Ministerio de Economía y Competitividad y dirigido por los profesores María Asenjo González y David Alonso García, en el que participa el primero. Finalmente, Raúl González Arévalo es responsable del texto de los epígrafes 1, 3, 3.2, 4 y 5. Tommaso Vidal ha redactado los epígrafes 2 y 3.1 , y es responsable de la transcripción del apéndice (6).

Así se puso de manifiesto hace unos años en González Arévalo, "Presencia diferencial”, p. 188.

LÓPEZ DE COCA CASTAÑer, "Las galeras venecianas".

6 GonzÁlez Arévalo, "Vecinos y propietarios" e "Integración y movilidad social".
} 
El recurso a las fuentes italianas -a las propias venecianas en particular- está arrojando nuevas perspectivas sobre el peso de los intereses de la República de San Marcos en el sur de la península ibérica. Así lo han puesto de manifiesto publicaciones recientes sobre la actividad comercial veneciana en el Reino de Granada, en Sevilla, y más aún en Cádiz, donde la presencia de embarcaciones de titularidad privada y el alcance de las operaciones mercantiles se han revelado muy superiores a lo que se consideraba hasta no hace mucho. ${ }^{7}$

En este nuevo estado de conocimientos un aspecto concreto hasta ahora desatendido emerge con fuerza: la diplomacia mercantil desplegada por Venecia en Castilla y en la península ibérica en general, materializada en las embajadas enviadas a lo largo del siglo XIV y en la apertura de sedes consulares: primero en Sevilla (1402-1407), con una actividad intermitente a lo largo del siglo XV; posteriormente en Cádiz (1424) y por último en Sanlúcar de Barrameda (1468), si bien con una jerarquía clara entre ellas, manifiesta tanto en la consideración otorgada por la propia república a cada una de las plazas como en los mecanismos previstos para su financiación y los representantes elegidos para ocupar el cargo. ${ }^{8}$

Dejando de lado la embajada de Marco Giustinian ante Fernando III en 1252, poco después de la conquista de Sevilla (1248), para pedir ayuda para Balduino II, asediado en su Imperio latino de Constantinopla, ${ }^{9}$ lo cierto es que los contactos diplomáticos más fluidos entre Castilla y Venecia se desarrollaron a partir del siglo XIV, presumiblemente tras la puesta en funcionamiento de la muda de Flandes en 1315, con Cádiz como una de sus escalas principales en la ruta atlántica. ${ }^{10}$ Este es el contexto que explica la misión de Desiderato Lucio en 1357 para solicitar a Pedro I patentes de seguro para el convoy de Poniente, una documentación que le fue concedida. ${ }^{11}$

Sin embargo, no siempre se respetaban los salvoconductos y en marzo de 1359 una coca veneciana fue capturada con su cargamento cuando se dirigía a Mallorca por galeras y cocas castellanas, lo que obligó al Senado a organizar una embajada en junio de ese año para solicitar al monarca que las restituyera. Incluso se solicitó la mediación del famoso dogo genovés Simone Boccanegra, aliado del rey de Castilla. El encargado de la misión fue el notario Andrea Buonguadagni, a quien en febrero de 1360, de regreso ya hacia Venecia, se le encomendó que sustituyera al embajador en Aragón, Francesco Cocco. ${ }^{12}$ En agosto de 1374, reinando ya Enrique II, el monarca castellano concedió carta de seguro y libertad de tránsito y comercio en todos sus dominios a los ciudadanos vene-

\footnotetext{
Véanse las publicaciones de GonzÁlez Arévalo, "Acordes y desacuerdos”, "Galeras y mercaderes venecianos", "Del Guadalquivir al Nilo", "De la laguna al océano", "Del Adriático al Atlántico".

8 González Arévalo, "Cum necessarium" y "En el Rio di Sibilia".

9 Mariutti de Sánchez Rivero, "Da Veniexia”, p. 444.

10 Una buena síntesis de la muda de Flandes en STöckLY, Le système, pp. 152-165.

11 Orlando (ed.), Venezia - Senato, Registro XXVIII (1357-1359), §41, p. 21. Las patentes de seguro en Archivio di Stato di Venezia (en adelante ASVe), Commemoriali, reg. 5, fol. 92vo , 21-III-1357.

12 Levantino (ed.), Venezia - Senato, Registro XXIX (1359-1361), §59, p. 28; §103, p. 54; §413, p. 226. Da noticias del salvoconducto castellano, conservado en Venecia, Inés Melero, aunque una errata lo fecha en 1395 en vez de 1359. Cf. Melero Fernández, "Fondos medievales”, p. 357.
} 
cianos, en respuesta a las misivas enviadas por el dogo de la república con Giovanni di Guant. Al mismo tiempo, pedía el mismo trato para los castellanos que acudieran a los territorios de la república. Apenas un mes más tarde escribió a los oficiales de la Corona de Castilla, a los que notificó que las embarcaciones, los súbditos y las mercancías venecianas se encontraban bajo su protección. ${ }^{13}$

Así pues, en el último cuarto del siglo XIV la presencia en las costas andaluzas de embarcaciones venecianas iba en aumento, y con ellas los tratos de sus mercaderes, que sin embargo no contaban con ningún marco oficial que regulara esa actividad. En consecuencia, en febrero de 1383, aprovechando el viaje planeado por ser Egidio Mauroceno y Nicolao de Olto, "civibus nostris qui vadunt ad partes Sibilie per actum mercationum" se debatió en el Senado que, ante la ausencia de tratado alguno con el rey de Castilla, "possint nomine suo et aliorum mercatorum nostrorum patizare et conponere ac facere sicut eis videbitur". Pero no solo. Definida Castilla como "locus insolitus" donde "non sunt asueti nostri mercatores", se decidió entregarles credenciales para que lograran las mejores condiciones posibles para los ciudadanos, mercaderes y embarcaciones que se dirigieran a Castilla. ${ }^{14}$

El éxito de la misión fue inmediato, pues en abril de ese mismo año Juan I de Castilla otorgaba a los venecianos los mismos "previllegios e franquezas e libertades segúnd los han los ginoveses e catalanes" y les facultaba para abrir una lonja y consulado en Sevilla. ${ }^{15}$ Sin embargo, el desarrollo posterior de los acontecimientos deja claro que fue un esfuerzo parcialmente baldío. Es lo que cabe deducir a tenor de las circunstancias que rodearon la confirmación de dicho privilegio tres lustros más tarde, en noviembre de 1398. Un incidente en el Mediterráneo oriental entre algunas embarcaciones vizcaínas al servicio del rey de Chipre y la muda de Beirut cuyo capitán era Marco Faliero condujo a la represalia de la nave del veneciano Gasparino Mauroceno en Cádiz, donde fue retenida y toda la mercancía descargada. Así lo comunicó en julio el soberano castellano al dogo veneciano, de modo que a principios de septiembre el Senado acordó que Antonio Spalatino iría como embajador ante Enrique III "procurando liberatione navis ser Gasparini Mauroceno et carici retenti in loco vocato Gades". Una vez más la misión concluyó con éxito, pues la nave de Gasparino Mauroceno fue liberada y Antonio Spalatino regresó a Venecia en noviembre con la confirmación del privilegio de Juan I. ${ }^{16}$

Parece más probable que la ratificación de las exenciones y la facultad de abrir un consulado en Sevilla fuera un nuevo impulso a las relaciones entre Castilla y Venecia, más que una mera certificación de las buenas relaciones existentes. El tono de las discusiones en el Senado así lo apunta y una cosa es segura: el consulado veneciano no había abierto aún en 1398, quince años después de obtener el permiso para hacerlo.

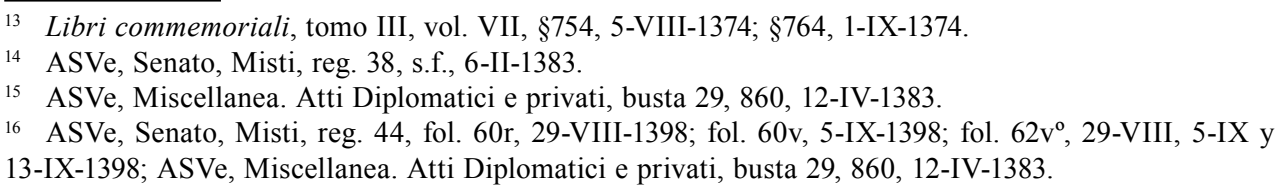


Con todo, aún tendrían que pasar otros cuatro años para que se abriera la sede sevillana, en un contexto global de apertura de la Serenísima al sur ibérico y Occidente en general. Así lo puso de manifiesto la firma de un tratado comercial con el emirato nazarí de Granada en 1400, que conllevó la apertura de un consulado análogo en el puerto de Málaga. ${ }^{17}$ Las circunstancias concretas que llevaron a la apertura de la sede consular veneciana en Sevilla ya han sido estudiadas. ${ }^{18}$ El terreno parecía abonado, no solo por la renovación de los privilegios en 1398, sino sobre todo porque emergen las primeras informaciones de los inicios de un tímido arraigo de mercaderes venecianos en la ciudad. El máximo exponente lo constituye, por ahora, Simone di Bonafé, que en abril de 1400 se dirigía a instalarse en la capital del Guadalquivir, desde donde actuaría como factor del entramado de compañías de Francesco di Marco Datini, el famoso mercader de Prato, puesto que ocupó al menos hasta marzo de 1403, cuando cesan las noticias sobre su actividad. ${ }^{19}$

Así pues, en marzo de 1402 el Senado veneciano, consciente "cum necessarium sit habere consulem nostrum in Sibilia per bono mercatorum nostrorum conversantium in partibus illis", determinó que se eligiera "unus nostrus ambasiator et consul Sibilie". ${ }^{20}$ El elegido para el cargo fue ser Angelo Venier quondam ser Andrea, que a finales de otoño de ese mismo año ya se encontraba instalado en la capital del Guadalquivir, donde como cónsul se convirtió en cabeza de una pequeña comunidad en la que destacaba por derecho propio la actividad de Luca Falier, ciudadano veneciano que desempeñaría un papel relevante en la relación de la república con el territorio a lo largo del primer cuarto del siglo XV.

\section{Angelo Venier y Luca Falier, dos venecianos en Sevilla}

Como se ha apuntado más arriba, nuestros conocimientos sobre la presencia veneciana en Castilla todavía son muy limitados. Las razones que subyacen bajo semejante escasez de informaciones indudablemente son variadas y no se pueden imputar únicamente a la dispersión de la documentación disponible.

A diferencia de los genoveses, que no desdeñaban un arraigo estable e incluso la adquisición de la vecindad, da la impresión de que los ciudadanos de la Serenísima presentes en Andalucía se mantuvieron en su mayor parte como un cuerpo extraño respecto a la sociedad local, incluso en aquellos casos en los que, como veremos, sus intereses en esta zona del sur ibérico fueron bastante estables y prolongados en el tiempo. Como consecuencia de la mayor fluidez de esta presencia veneciana desde principios del siglo $\mathrm{XV}$, cualquier reconstrucción prosopográfica debe servirse casi obligatoriamente del material conservado en el Archivio di Stato de Venecia, si bien el exceso de documentación invita a la cautela en la reconstrucción de los perfiles de los mercaderes. Los dos

\footnotetext{
FÁBregas García, "Acercamientos y acuerdos".

Vid. supra nota 8.

9 GonzÁlez Arévalo, "Florentinos”, pp. 286-288.

20 ASVe, Senato, Deliberazioni, Misti, reg. 46, fol. 4r, 7-III-1402. Las condiciones internas desarrolladas en GonzÁlez Arévalo, "Cum necessarium”, en prensa.
} 
protagonistas del presente estudio, Angelo Venier $q$. ser Andrea sclavo y ser Luca Falier, aunque exponentes de dos familias nobles venecianas, son bastante difíciles de rastrear en los documentos vénetos, una dificultad aumentada por la frecuente homonimia en el ámbito de sus propias familias.

Angelo Venier era hijo de ser Andrea sclavo y, con toda probabilidad, debe identificarse con Angelo Venier da San Baseggio, mencionado en las «Genealogie patrizie» de Marco Barbaro. ${ }^{21}$ A diferencia de ser Luca Falier, cuyo perfil desarrollaremos en breve, se puede decir muy poco de este Angelo Venier. A pesar de haber sido llamado a ocupar un cargo importante, el de primer cónsul veneciano en Sevilla, no parece haber dejado un rastro importante en la documentación, si bien tampoco se puede descartar que aún puedan aparecer nuevos documentos entre los importantes fondos venecianos.

Nombrado por el Senado para la representación consular en la capital hispalense el 9 de marzo de 1402, ciertamente Venier no debía ser un joven inexperto. Probablemente llegó a la capital del Guadalquivir en otoño de ese año, permaneciendo hasta el 'cierre' del consulado en $1407 . .^{22}$ En realidad su mandato debía haber finalizado en 1404, al cumplirse los dos años establecidos con prudencia por el Senado para obtener mejores condiciones para los mercaderes venecianos que comerciaban en la Corona de Castilla. De hecho, en la carta que le escribió el Senado el 10 de abril de 1404, en respuesta a otra del cónsul desde Sevilla con fecha 16 de febrero, se le comunicaba la llegada inminente de su sustituto, que debía partir hacia Andalucía a lo largo de ese mismo mes. ${ }^{23}$ Por motivos todavía no dilucidados, el recambio no debió llegar nunca a Sevilla dado que en junio de 1407 el Senado deliberó que, a la vista de los escasos beneficios y los altos costes de mantenimiento del consulado veneciano en la ciudad, una vez terminado el mandato de Angelo Venier los mercaderes de la república presentes en la ciudad debían elegir un vicecónsul. ${ }^{24}$

A partir de ese momento se puede considerar que la experiencia andaluza de Angelo Venier, poco fructuosa según admite el propio Senado, llegó definitivamente a su fin y las noticias sobre su persona se vuelven más esquivas. Se sabe que en 1409 y en 1415 inscribió a dos de sus hijos, el primogénito Andrea y a Marco, en la Balla d'Oro, en cuyos registros se enumeran los nombres de los patricios que participaban en el sorteo previsto el día de Santa Bárbara para la admisión en el Maggior Consiglio, el máximo órgano político de la República de San Marcos. ${ }^{25}$ Una década más tarde, en junio de 1424, probablemente ya en edad avanzada, rechazó una nueva misión diplomática ante el rey de Castilla para recuperar las mercancías de la galera Pasqualiga, saqueada por

21 ASVe, Miscellanea codici, Storia Veneta, «Genealogie patrizie», VII, fols. 235-236.

22 González Arévalo, "Cum necessarium".

23 ASVe, Senato, Deliberazioni, Misti, reg. 46, fol. 127r, 10-IV-1404: "quia de brevi sumus misuri vestrum cambium ad illas partes qui venit ambasiator et consul et est recessurus hinc per totum mensem presentem".

24 ASVe, Senato, Deliberazioni, Misti, reg. 47, fol. 121r, 28-VI-1407: "e conplido che havria ser Anzolo Venere el so tempo, tra i marchadanti se faza un viceconsolo”. Desarrollado en GonZÁLEZ ArÉvALO, "Cum necessarium".

25 ASVe, Avogaria di comune, Balla d'Oro, reg. 162-I, fol. 146v. 
vizcaínos. ${ }^{26}$ Después los documentos enmudecen y no es posible seguir más a fondo las vicisitudes personales de nuestro hombre. Por otra parte, en el estado actual de conocimiento, no se sabe si el cónsul tenía intereses comerciales y personales en Andalucía, pero se puede suponer, a partir con la comparación de la trayectoria humana y vital de Luca Falier, que la estancia andaluza de Angelo Venier fue un asunto estrictamente político y diplomático.

Por su parte, la documentación sobre Luca Falier es definitivamente más abundante. La carta de Angelo Venier de 15 de febrero de 1404, reproducida en el apéndice, ya lo sitúa en Sevilla en esas fechas. El tono cordial y la mención de asuntos personales y comerciales por parte del cónsul permite suponer una cierta familiaridad entre ambos, aunque nada indica que Falier desempeñara un cargo oficial en el consulado de Sevilla. ${ }^{27}$ En realidad Luca estaba activo en Castilla junto con su hermano Giovannino al menos desde 1402, como sugiere la carta de Bernal González a Enrique III. ${ }^{28}$

A diferencia de Venier que, como se ha visto, se desplazó a Castilla por motivos puramente diplomáticos, Falier debía tener intereses comerciales bastante importantes en el Mediterráneo occidental. De hecho, en 1410 el Senado veneciano le envió en calidad de "viceconsolo in Castela" indicaciones sobre las modalidades de subvención fiscal del propio consulado, que ya no se financiaba con tasas sobre las mercancías importadas y exportadas en la zona. ${ }^{29}$ En consecuencia, debió ser elegido, quizás ya en 1407, entre los mercaderes venecianos que operaban en Andalucía, como preveía la deliberación sobre el cierre del consulado. Sin embargo, los intereses económicos de Falier aquí se pueden remontar al menos a 1404 e incluso antes, como confirmaría su presencia entre los mercaderes damnificados por el ataque genovés a la coca del veneciano Nicolò Rosso, ${ }^{30} \mathrm{y}$ como certifica de nuevo la carta de Angelo Venier, que lo señala a punto de partir para Berbería, aunque no está especificada la finalidad del viaje. No se puede descartar que no se tratara de un viaje aislado, aunque no tengamos más indicios en este sentido, pero cabe recordar que el propio Senado de la república reconoció el intenso comercio de media distancia que desarrollaban los mercaderes venecianos a escala interregional, pues en 1408 reservó un tributo preferencial para el tráfico entre Sevilla y el Magreb por valor de "unam octavam per centenario" ( 0 ' $125 \%$ ), frente al 1\% que gravaba el trayecto Venecia-Sevilla y el 0' $5 \%$ de la ruta inversa durante el tiempo que estuvo abierto el consulado entre 1402 y $1407 .{ }^{31}$

\footnotetext{
26 ASVe, Senato, Deliberazioni, Misti, reg. 55, f. 34v, 17-VI-1424. Una parte de la deliberación de abril de 1424, que finalmente no fue aprobada, preveía además que el embajador permaneciese de nuevo en Sevilla como cónsul. ASVe, Senato, Deliberazioni, Misti, reg. 55, fol. 13v, 10-IV-1424.

27 ASVe, Procuratori di S. Marco, Misti, Commissarie, b. 85a, fasc. VI, lettera Siviglia-Venezia [15-II1403 more veneto], fol. 1v: "per ser Lucha Falyer fo mandado con perle a uno baron de sta corte"; "pur de sty fati, àme dado asay despyaser quanto ho dito. Se'l fose myo fyo, non farya pur a darly hogny cason el sye qua ben zerto e'l sa asay [lectura incierta] zerto per tegnerse saver quelo el sa i schavaza e'l cola. Non voray per so ben de luy el savese tanto".

28 Véase el epígrafe 4.

29 ASVe, Senato, Deliberazioni, Misti, reg. 48, fol. 179v, 20-IX-1410.

30 Braunstein, "La capture", p. 118.

31 ASVe, Senato, Deliberazioni, Misti, reg. 47, fol. 178v, 20-III-1408. Aspectos desarrollados en González Arévalo, "Cum necessarium".
} 
En 1413 ya debía haberse alejado de Sevilla, si bien es probable que permaneciera en el ámbito ibérico, pues se ofreció al Senado para ocuparse personalmente de un episodio de piratería de catalanes contra las naves de Bartolomeo Solari y Cristoforo Conzanave, y que le había perjudicado en primera persona. ${ }^{32}$

En los años posteriores se le puede ver activo con embarcaciones privadas en un amplísimo espacio comercial que se extendía desde Rodas a Inglaterra, como por otra parte era habitual para un mercader veneciano de la época, sobre todo en el contexto de la navegación privada. En diversas ocasiones entre 1417 y 1422 se desplazó entre el Atlántico y el Mediterráneo occidental, comerciando sin duda por cuenta propia y fletando su propia nave de titularidad privada a mercaderes de otras ciudades italianas. Así, en 1417 era patrón de una nave "presentialiter ad viagium Flandrie", ${ }^{33}$ mientras que en 1421 y 1422 cargó lana inglesa por cuenta de compañías florentinas, con destino a Cádiz y Porto Pisano. ${ }^{34}$ No es posible saber si el cuero que en 1425 envió junto a Giovanni Zorzi a las ferias de Las Marcas era de origen andaluz, ${ }^{35}$ pero lo que sí es seguro es que siguió desarrollando con éxito misiones diplomáticas para la Serenísima. En 1423, encontrándose quizás en Cataluña, donde había trasferido parte de sus intereses ya en 1413, propuso al Senado desplazarse en persona a Génova para tratar la indemnización por daños para las naves de Andrea Arian y Giacomo Pampano. ${ }^{36}$ La última noticia que relaciona a Luca Falier con la península ibérica se remonta a 1429, año en el que se encontraba con seguridad en Cataluña, ocupado en la defensa de los intereses del veneciano Cristoforo da Canal y buscando obtener, en vano, una solución para las tensiones entre venecianos y catalanes sobre la tasación (leude) che los segundos exigían a las galeras de Flandes. ${ }^{37}$ En el estado actual de conocimiento no contamos con informaciones sobre Falier después de esta última fecha, pero se puede afirmar razonablemente que en adelante ya no estuvo implicado en misiones diplomáticas en la península ibérica.

La parábola de Angelo Venier y Luca Falier, aunque solo se pueda reconstruir con limitaciones, refleja en todo caso de manera bastante evidente la actitud de Venecia hacia el Mediterráneo occidental y la península ibérica. A una primera fase, caracterizada por el recurso a personal consular y diplomático específicamente nombrado y enviado por el Senado, encarnada por la breve e infructuosa experiencia de Angelo Venier en Sevilla, pero también por el consulado de Málaga, siguió una segunda, más duradera, en la que prevaleció el empleo de mercaderes que ya estaban activos en la zona, o incluso de personal autóctono. ${ }^{38}$

\footnotetext{
ASVe, Senato, Deliberazioni, Misti, reg. 49, fol. 187r, 2-VI-1413.

ASVe, Senato, Deliberazioni, Misti, reg. 52, fol. 51v, 26-X-1417.

TognetTI, "Galeras estatales", pp. 131-132.

ASVe, Senato, Deliberazioni, Misti, reg. 55, fol. 91v, 22-II-1425.

ASVe, Senato, Deliberazioni, Misti, reg. 54, fol. 99v, 27-IV-1423.

ASVe, Senato, Deliberazioni, Misti, reg. 56, fols. 175rv, 23-III-1429; ASVe, Senato, Deliberazioni, Misti, reg. 57, fol. 125r, 5-VII-1429. La cuestión de las lezdas era objeto de la diplomacia veneciana en la Corona de Aragón desde 1403. ASVe, Senato, Deliberazioni, Misti, reg. 46, fols. 100v-102r, 10-IX-1403.

38 Sería el caso de dominus Nicolò de Pax, cónsul veneciano en Mallorca, confirmado en 1409 (ASVe, Senato, Deliberazioni, Misti, reg. 48, fol. 73v, 29-IV-1409) y de Bartolomé García, vecino de Cádiz,
} 


\section{Un ataque y una carta}

Un año después de haberse establecido en Sevilla Angelo Venier tuvo que hacer frente a su misión más difícil como cónsul en la ciudad. Efectivamente, la coca de Nicolò Rosso fue atacada en el puerto de Cádiz por otras dos cocas genovesas lideradas por el corsario ligur Nicolò da Moneglia, en represalia por la derrota y la captura de tres galeras genovesas en la bocha de Zionclo - uno de los dos accesos a la bahía de Navarino, al norte de Modona, en el Peloponeso- a manos del famoso Carlo Zeno, el reputado almirante veneciano, artífice de la victoria de la Serenísima en la Guerra de Chioggia contra Génova (1378-1381). ${ }^{39}$

Hasta hace muy poco tiempo era completamente desconocida la actuación de Angelo Venier en Castilla. Las deliberaciones del Senado veneciano confirman que el 15 de diciembre de 1403 había enviado una carta desde Sevilla en la que relataba las gestiones realizadas cum rectoribus Sibilie, así como la audiencia con Enrique III. La actitud solícita de Venier y otra carta remitida por el nobilem virum Luca Faliero hicieron concebir esperanzas sobre la reacción del monarca castellano, que se habría mostrado tajante acerca ante este tipo de incidentes en sus aguas. La Serenísima contestó que si antes de que le llegaran sus órdenes Venier conseguía recuperar la coca y el cargamento, debía examinarlo con la copia que incluían con el detalle de la parte de cada mercader. Según cómo viera la situación, quedaba a su criterio presentar o no al rey las cartas remitidas, en función de lo que fuera más útil para recuperar la embarcación y su carga. ${ }^{40}$ Evidentemente, ni el cónsul ni el Senado debían saber a esas alturas que Nicolò da Moneglia se había dirigido hacia Brujas con su presa.

Dos meses más tarde, a mediados de febrero, Angelo Venier remitía una nueva carta desde Sevilla, leída en el Senado en abril de $1404 .{ }^{41}$ Hasta ahora se trataba de la última noticia sobre el asunto desde Castilla. ${ }^{42}$ Sin embargo, la localización de otra carta -reproducida en apéndice- en los archivos venecianos permite ampliar la perspectiva del cónsul veneciano sobre el asunto y, especialmente, sobre su propia misión diplomática en la corona castellana.

\subsection{La coca de Nicolò Rosso: un ejemplo del tráfico privado veneciano}

La captura de la coca de Nicolò Rosso, muy detallada y por lo tanto bien analizable gracias a la documentación abundante que ha sobrevivido, no es más que una pequeña pieza en una fase de tensiones entre Venecia y Génova, con origen en Oriente tras el

nombrado cónsul veneciano en la ciudad a petición propia y atendiendo a su buena actuación previa al servicio de los intereses venecianos (ASVe, Senato, Deliberazioni, Misti, reg. 55, fol. 16v, 12-IV-1424).

39 Se ocupó del incidente en primer lugar BRAUnSTEIn, "La capture".

40 ASVe, Senato, Deliberazioni, Misti. Registri, registro 46, fol. 122 y vo , 31-I-1403 (more veneto). El año veneciano comenzaba el 1 de marzo, de modo que la sesión corresponde al 31 de enero de 1404.

${ }^{41}$ ASVe, Senato, Deliberazioni, Misti. Registri, reg. 46, fol. 127r, 10-IV-1404.

42 González Arévalo, "Cum necessarium”, en prensa. 
saqueo de Beirut y Trípoli llevado a cabo por el lugarteniente francés en Génova, Jean de Le Meingre, llamado Boucicaut. ${ }^{43}$ Después de un primer acuerdo poco concluyente, firmado en Venecia el 22 de marzo de 1404, no cesaron los actos de piratería, con frecuencia protagonizados por Nicolò da Moneglia por orden de Boucicaut. La escasa predisposición de Génova a pagar las indemnizaciones pactadas obligó a las partes a redactar nuevos acuerdos, el 28 de junio de 1406, en previsión de un arbitraje ante la República de Florencia. La controversia solo se resolvió en 1408 con una sentencia arbitral pronunciada por el conde de Saboya el 9 de agosto, ${ }^{44}$ que establecía, entre otras cuestiones, que Génova debía pagar 12.053 ducados y 4 grossi de la moneda saboyana para los daños sufridos por la coca de Nicolò Rosso y sus mercancías. ${ }^{45}$ De cualquier modo, al margen del interesante contexto de la controversia vénetogenovesa, con sus fases "elásticas" de endurecimiento y relajación de la tensión, las peticiones de indemnización realizadas por Venecia a Génova ofrecen interesantes indicios sobre la navegación privada veneciana y sobre su relevancia económica, así como sobre su carácter complementario respecto a la navegación institucional en convoyes de galeras. ${ }^{46}$ Efectivamente, en un lapso de pocos meses, entre octubre y diciembre de 1403 , los genoveses capturaron tres naves privadas venecianas en el Mediterráneo occidental, a las que se añaden otras dos capturadas en los últimos meses de 1404 (tabla 1).

\footnotetext{
43 Para la cuestión de la coca de Nicolò Rosso ya nos hemos remitido a BRAUnstein, "La capture". Para el contexto político véase BALARD, "La lotta contro Genova". El nexo de unión entre el episodio y el sistema de relaciones entre las dos repúblicas y los Mamelucos en Oriente emerge con fuerza en la publicación de Fuess, "Why Venice".

44 Posteriormente los pagos se aplazaron hasta 1417. La cuestión está bien reconstruida en BraunsteIn, "La capture". La serie de acuerdos y la sentencia se conservan en ASVe, Commemoriali, reg. IX, fols. $165 \mathrm{r}-167 \mathrm{v}$ y ASVe, Commemoriali, reg. X, fols. 10r-13v, 148r-162v. Para las relaciones diplomáticas entre las dos repúblicas y sobre todo para la vertiente genovesa de la documentación nos remitimos a SuRdich, Genova e Venezia fra Tre e Quattrocento, con un riquísimo apéndice documental.

45 ASVe, Commemoriali, reg. X, f. 155r.

46 Para una puesta en valor de la navegación privada veneciana, con un intento de aproximación cuantitativa, nos remitimos a Cogdon, "Private Venetian ships".
} 
Et sCribatur Viro nobili ser Angelo Venerio, consuli nostro Sibilie. Acción consular...

Tabla 1. Capturas genovesas de naves privadas venecianas en Occidente (1403-1404) ${ }^{47}$

\begin{tabular}{|c|c|c|c|c|}
\hline Año & Patrón & Trayecto & Detalles de la captura & $\begin{array}{l}\text { Detalles del } \\
\text { cargamento }\end{array}$ \\
\hline 1403 & $\begin{array}{l}\text { Giovanni } \\
\text { Obizo }\end{array}$ & Mallorca-Venecia & & $\begin{array}{l}\text { pieles }(20.000-22.000 \\
\text { ducados })^{48}\end{array}$ \\
\hline 1403 & $\begin{array}{l}\text { Antonio } \\
\text { Coppo }\end{array}$ & Ibiza-Venecia & Capturada en Ibiza & $\begin{array}{l}\text { lana y otras mer- } \\
\text { cancías (daños: } 81 \\
\text { sacas de lana (647 } \\
\text { florines) })^{49} ; 213 \text { sacas } \\
\text { de lana. }{ }^{50}\end{array}$ \\
\hline 1403 & Nicolò Rosso & Venecia-Flandes & $\begin{array}{l}\text { Capturada en Cádiz } \\
\text { por Nicolò da Mo- } \\
\text { neglia }\end{array}$ & $\begin{array}{l}\text { Mercancías varias } \\
\text { (50.000 ducados; } \\
\text { daños por } 16.071- \\
23.801 \text { ducados })^{51} \\
\end{array}$ \\
\hline 1404 & $\begin{array}{l}\text { Antonio } \\
\text { Coppo } \\
\end{array}$ & Cartagena-Venecia & $\begin{array}{l}\text { Capturada en Sicilia } \\
\text { por los Spinola }\end{array}$ & Balas de lana ${ }^{52}$ \\
\hline $1404 ?$ & $\begin{array}{l}\text { Francesco } \\
\text { Pessato }\end{array}$ & Sevilla-Alejandría & $\begin{array}{l}\text { Capturada por piratas } \\
\text { vizcaínos, a los que la } \\
\text { sustrae Lionello } \\
\text { Lercari }\end{array}$ & Aceite $^{53}$ \\
\hline
\end{tabular}

El cuadro que emerge confirma la amplitud y la importancia, infravaloradas, de la navegación privada veneciana en el Mediterráneo occidental, con trayectos que con frecuencia calcaban los de los convoyes de galeras pero que en ocasiones también podían seguir otras rutas, saltándose decididamente el paso por Venecia. A las naves perjudicadas hay que añadir otras tres naves venecianas que escaparon a los asaltos genoveses: la Concianave, la Solera y la nave de ser Taddeo de Benedicto. ${ }^{54}$ Un primer acercamiento no sistemático al epistolario datiniano entre Venecia y la península ibé-

\footnotetext{
47 Elaboración propia con las naves privadas venecianas activas en el Mediterráneo occidental envueltas en el proceso contra Génova. En cursiva se ofrece el valor de los daños no confirmados, tal y como se recogen en el diario-crónica de Antonio di Marco Morosini.

48 ASVe, Commemoriali, reg. IX, f. 167r; Il Codice Morosini, p. 225.

49 Surdich, Genova e Venezia, p. 181; ASVe, Commemoriali, reg. X, f. 10v.

50 Archivio di Stato di Prato (en adelante ASPo), Datini, busta 1072.5 / 800805, Ibiza-Mallorca, 16-XI1403. Sobre la nave había embarcados, con destino Venecia, 53 sacas de la comisaría de Zanobi di Taddeo Gaddi, 100 sacas de ser Antonio Contarini y 60 sacas de Paoluccio di maestro Paolo da Camerino, todos corresponsales de Francesco Datini en la laguna.

51 Il Codice Morosini, p. 226; ASVe, Commemoriali, reg. X, f. 155r. Para el cargamento de la nave de Nicolò Rosso véase también Braunstein, "La capture”, pp. 115-117.

52 ASVe, Commemoriali, reg. X, f. 12r.

53 ASVe, Commemoriali, reg. X, f. 11v.

54 ASPo, Datini, b. 994.4 / 420926, Ibiza-Valencia, 10-X-1403; b. 928.3 / 515131, Venezia-Barcellona, 21-XII-1403.
} 
rico sacó a la luz el movimiento y las operaciones de las naves privadas venecianas. ${ }^{55}$ Estas no se movían solo sobre la base de la navegación de Estado, sino que atraían el interés de una tupida red de intercambios de corto y medio radio entre Cartagena y los puertos sicilianos y del Tirreno, con el archipiélago balear actuando como nodo central $(h u b) .{ }^{56}$ Las filiales y los corresponsales de Datini en la península ibérica se sirvieron ampliamente de las naves privadas venecianas, ya fuera para operaciones por cuenta propia, ya como comisionarios de los corresponsales en Venecia, cargando sobre todo lana de San Mateo, Tortosa y Mallorca.

Volviendo a las naves perjudicadas por los genoveses, la más interesante y la que ofrece más consideraciones detalladas es la coca de Nicolò Rosso, que ocupa un lugar particularmente importante tanto en la documentación procesal como en la carta de Angelo Venier cuya edición se ofrece. Del viaje de la nave, partida directamente desde Venecia a juzgar por la carga, sabemos muy poco antes de su llegada a Cádiz en el mes de diciembre de 1403. Aquí fue capturada de noche por el genovés Nicolò da Moneglia, probablemente pocos días antes del 15 de diciembre, y conducida a Brujas. ${ }^{57}$ Las fuentes son unánimes a la hora de identificar como destino final del viaje Flandes pero, según Philippe Braunstein, el cargamento, minuciosamente descrito en un fascículo procesal del 2 de mayo de 1405, no parece ser el habitual con destino al mar del Norte. ${ }^{58} \mathrm{El}$ investigador francés subraya en particular la escasa incidencia de algodón y pimienta, así como la ausencia de clavo frente a una gran cantidad de especias procedentes del océano Índico. Por otra parte, Antonio di Marco Morosini afirma en su diario-crónica que la nave transportaba en el momento de la captura "specie e zucari per la vaiuda de duchati XL milia d'oro e de gotoni per la vaiuda de duchati X milia d'oro". ${ }^{59}$ Sobre el valor de las cifras de Morosini, en otros casos bastante preciso, hay dudas razonables dado que los propios venecianos declararon poco después un valor de 23.801 ducados en el momento de la captura. ${ }^{60}$ Cualquiera que fuera su valor efectivo, es probable que el algodón fuera más importante de lo que emerge en el pliego procesal de 1405 que, cabe recordar, constituye únicamente un elenco de los daños sufridos, no el manifiesto de carga de la nave. De todos modos, las diferencias de mercancías entre el cargamento habitual de las galeras de Flandes y la nave de Nicolò Rosso no se pueden reducir a una extravagancia particular de este último, sino que entraban dentro de la dinámica normal del comercio con embarcaciones privadas. ${ }^{61}$ De hecho, sabemos por una carta de un corresponsal de la compañía Datini en Málaga, Tuccio di Gennaio, fechada el 23 de marzo de 1403, que la nave de Nicolò Rosso surcaba habitualmente la ruta comercial

\footnotetext{
55 Una primera aproximación en CoNGDON, "Private venetian ships" y "Datini and Venice", centrado sin embargo en la circulación de noticias sobre la batalla de Modona.

56 Sobre el papel de Ibiza en el sistema de intercambios que unía el Mediterráneo y el mar del Norte véase OrLANDI, "Ibiza".

57 Braunstein, "La capture”, pp. 111-112; Il Codice Morosini, p. 226.

58 Braunstein, "La capture”, pp. 116-117.

59 Il Codice Morosini, p. 226.

60 ASVe, Commemoriali, reg. X, f. 155r.

61 Montemezzo (ed.), Giovanni Foscari, pp. 39-41.
} 
entre Venecia y Flandes. ${ }^{62}$ Entre el otoño de 1402 y la primavera de 1403 realizó el viaje de ida y vuelta desde la laguna hasta el mar del Norte, tal vez el último antes de su captura. Desde Flandes se había desplazado hasta Inglaterra, donde se había detenido durante cierto tiempo, quizás buscando lana inglesa. La coca de Rosso partió de Falmouth, en Cornualles, el 13 de marzo, haciendo escala en Málaga el 21 de ese mes, antes de continuar hacia Ibiza con la intención de comprar sal y transportarla hasta Venecia. ${ }^{63}$

Entre los mercaderes que cargaron mercancías en la nave de Nicolò Rosso en el desventurado viaje de 1403 resulta complicado establecer quién tenía intereses comerciales únicamente en el mar del Norte y quién operaba también en los mercados del Atlántico ibérico (Sevilla, Cádiz) solo a partir del listado de daños. De hecho, la Tariffa de Bartolomeo Pasi, de principios del siglo XVI, parece mostrar una cierta similitud entre las mercancías demandadas en Flandes y en los reinos ibéricos. ${ }^{64}$ Además de las especias omnipresentes, consisten principalmente en paños de seda, algodón hilado, fustanes y gorros de lana, artículos que están bien representados en el cargamento de la coca de Nicolò Rosso. ${ }^{65}$

Afortunadamente para los historiadores -y desafortunadamente para él- entre los mercaderes damnificados se encontraba también Luca Falier que, como se ha visto más arriba, era indudable que tenía intereses económicos en la península ibérica y en el momento de los hechos se encontraba en Sevilla. Lo interesante de la cuestión es que las mercancías que declaró son absolutamente particulares, completamente fuera del muestrario de Bartolomeo Pasi, más clásico. Efectivamente, Falier había cargado 15 barriles de salitre, destinados probablemente a los puertos del mar del Norte, así como dos paquetes (colli) de "schilatorum de sclavonia" (probablemente un tipo de pescado salado) con un total de 6.925 unidades. ${ }^{66}$ Se puede suponer que los mercados a los que se destinaban los "schilati" eslavos fueran precisamente Cádiz y Sevilla, no solo por la presencia de Falier allí, sino también por la difícil competencia que semejante mercancía habría encontrado en el mar del Norte, donde el comercio de pescado salado estaba dominado por los mercaderes hanseáticos. Por el contrario, el tráfico de Falier

\footnotetext{
62 ASPo, Datini, b. 1072 / 903196, Málaga-Mallorca, 23-III-1403. La carta ha sido publicada en FÁBREGAS GARCÍA, "Estrategias de los mercaderes", doc. 10. Consideramos que la fecha correcta de la carta es 1403 porque, aunque está datada en 1402, sigue el estilo florentino de la Encarnación, que hacía comenzar el año el 25 de marzo.

63 FÁbregas García, "Estrategias de los mercaderes", doc. 10: "A dì 21 giunsi qui la nave Ser Nicolao Roso. Viene di Fiandra va a Ieviza per comprar de cantero di sale per Vinegia; là starà 8 in XII dì. Idio mandi salvo. È molto partì di Fiandra, è stato molto in Inghiltera, fa 9 dì partì d'Inghiltera, de Falamua". Era frecuente que las embarcaciones venecianas privadas cargaran sal en Ibiza en el trayecto de regreso hacia la laguna, como estableció HocQuet, Il sale e la fortuna, pp. 74-75; por el contrario, Falmouth no era un punto habitual de aprovisionamiento de lana inglesa, aunque se conocen noticias esporádicas, como la galera genovesa que en 1324 cargó 4.000 sacas, según se recoge en MiLler y Hatcher, Medieval England, p. 222. La combinación de sal y lana inglesa era poco habitual pero, a falta de informaciones sobre el cargamento de este viaje, permanece como hipótesis.

${ }_{64}$ PAsI, Tariffa de' Pesi, pp. 185-189, 200-201.

${ }_{65}$ Braunstein, "La capture", p. 116.

66 ASVe, Miscellanea atti diplomatici e privati, b. 31, n. 918, n. XXXVIIII.
} 
con Berbería y el comercio de joyas y perlas con la aristocracia castellana, atestiguados en la carta de Angelo Venier, eran más seguros, además de clásicos. Asimismo, es posible que también estuviera activo en Cádiz Giovannino Falier, quizás hermano de Luca a tenor de las Genealogie patrizie ${ }^{67}$ Declaró daños en dos de los cuatro colli de semesanto $^{68}$ cargados en la coca, por valor de 18 libras y 6 sueldos de gros tournois. ${ }^{69}$ Giovannino había llegado a Castilla en junio de 1402, a bordo de la muda de Poniente, con un cargamento de paños que descargó en Cádiz y llevó consigo hasta Sevilla, donde finalmente acordó su venta a buen precio a oficiales reales, que los adquirieron por cuenta de Enrique III. ${ }^{70}$

La lista de daños al cargamento de la nave de Nicolò Rosso, por más que sea puntillosa en su redacción, revela poco sobre el comercio y sobre los operadores venecianos activos en los puertos andaluces. Sin embargo, resulta extremadamente preciosa, junto con la documentación del arbitraje del conde de Saboya, para arrojar una luz más amplia sobre el sistema de navegación privada veneciana en el Mediterráneo occidental. El cuadro que emerge se caracteriza por la vivacidad y rapidez de los intercambios organizados sobre embarcaciones privadas, y confirma la división y la especialización por mercancías entre las galeras institucionales y las embarcaciones privadas. Además, es posible distinguir una cierta continuidad entre los operadores activos en el Mediterráneo occidental, como era el caso de Concianave y de Antonio Coppo, que recorrían de manera repetida las mismas rutas. El epistolario datiniano, magistralmente estudiado por Angela Orlandi para esta área, ${ }^{71}$ no ha dejado de ser una mina de informaciones al respecto, y un estudio sistemático indudablemente permitiría reconstruir en detalle la red de operadores privados venecianos entre el Mediterráneo occidental y el Atlántico.

\subsection{Comunicación diplomática, acción consular y estrategia mercantil veneciana}

La carta de Angelo Venier, que se ofrece en apéndice y está en el origen de este estudio, constituye un unicum por ahora, pues hasta el momento no han emergido otras comunicaciones de cónsules venecianos en la Castilla del siglo XV. Afortunadamente se trata de un escrito muy extenso, con múltiples informaciones para profundizar en dos temas de gran interés: la resolución de conflictos entre naciones mercantiles extranjeras en suelo castellano y la estrategia veneciana para abrirse paso y afianzarse en un nuevo mercado. La misiva está fechada el 15 de febrero de 1404 (1403 siguiendo el more veneto, que hacía comenzar el año el 1 de marzo) y fue recibida "In Venyes die primo avril", como confirma una anotación, obra de mano ajena. En consecuencia, la carta tardó un mes y

\footnotetext{
67 ASVe, Miscellanea codici, Storia Veneta, «Genealogie patrizie», III, p. 451.

68 Semesanto (semenzina en el original italiano): especia procedente de la semilla de una hierba del reino de Basán que llegaba a través de Persia.

69 ASVe, Miscellanea atti diplomatici e privati, b. 31, n. 918, n. XL. El posible interés en Castilla lo sugiere la restitución en Cádiz de uno de los dos colli.

70 Véase las informaciones contenidas en la carta analizada en el epígrafe 4.

71 Orlandi, "Ibiza".
} 
medio en recorrer la distancia entre Sevilla y Venecia, el mismo plazo de tiempo que necesitó otra anterior fechada el 15 de diciembre de 1403 y leída ante el Senado de la república el 31 de enero de $1404 .^{72}$

Lo primero que cabe señalar es que la carta no es una comunicación oficial, como otras que las actas del Senado confirman que el cónsul remitió desde Sevilla, como era el caso, por ejemplo, de otra redactada al día siguiente de nuestra comunicación, el 16 de febrero de 1404, a la que la asamblea de la república dio contestación el 10 de abril siguiente. ${ }^{73}$ De hecho, hasta el momento suponía la última información recabada sobre la labor consular de Angelo Venier en la capital hispalense, pues las noticias de junio de 1407 se refieren al cierre de la sede diplomática. Lo confirma no tanto la lengua vernácula empleada, el vulgar veneciano, habitual en los despachos diplomáticos, ${ }^{74}$ como el tono desenfadado, familiar, que el cónsul emplea, empezando por el propio encabezamiento, "per mi barba", teniendo en cuenta que en vulgar veneciano la voz 'barba' significa 'tío', revelando la cercanía de trato y un posible parentesco con el destinatario. De hecho, los receptores no fueron ni el dogo, a la sazón Michele Steno (1400-1413), ni el Senado veneciano. Así, la carta está dirigida al potente miles Gabryely Aymo y a un honorbile Zany, "venyziarum dette", que no ha sido posible identificar por el momento, ni entre los parientes de Angelo Venier, ni entre las autoridades de la república. En la misma línea, los saludos de despedida incluyen diversos miembros de la familia más extensa, Piero Pisani, Cristina (presumiblemente la mujer de este último) y los "garzony", que bien podrían ser sus hijos, bien los sirvientes de la casa, parte de la familia en un sentido romano, de cuya relación concreta e identidad nada más podemos aportar. Para concluir esta primera aproximación sobre la naturaleza del texto, terminaría de confirmar el carácter no oficial el tratamiento informal que realiza Venier sobre temas oficiales, como son las gestiones para recuperar la coca de Nicolò Rosso y las mercancías robadas; o la estrategia veneciana para abrir mercado en Castilla. En última instancia, y de modo definitivo, los comentarios particulares que incluye sobre Luca Falier y asuntos que concernían a su vida privada resultan concluyentes en este sentido.

El hecho de que nos encontremos ante una comunicación informal no le quita la consideración diplomática. Efectivamente, hace tiempo que se ha superado la concepción que reducía la diplomacia a la gran narrativa oficial. Más aún, el texto recoge actividades que normalmente se estudian por separado y que formaban parte de la acción diplomática, esencialmente polivalente. Así, como se expondrá a continuación, están incluidas la recogida de informaciones, la negociación, la representación y la comunicación. Por último, la propia naturaleza informal de la misiva analizada, apenas señalada, recuerda

ASVe, Senato, Deliberazioni, Misti, reg. 46 (1402-1405), fol. 122 y vo, 31-I-1404.

Ibidem, fol. 127r, 10-IV-1404.

74 Como muestra pueden verse las comunicaciones remitidas desde Nápoles por el miles y orator veneciano Zaccaria Barbaro, en Corazzol (ed.), Dispacci di Zaccaria Barbaro. 
que los canales para la comunicación diplomática podían adoptar múltiples formas, y no solo los despachos, deposiciones y notificaciones institucionales. ${ }^{75}$

Esta carta no es la única que escribió Angelo Venier a sus corresponsales. Efectivamente, nada más empezar el escrito recuerda cómo había avisado previamente de la captura de la coca de Nicolò Rosso y de su intención de andar a la corte ("ve avysy de la presa de ser Nicholo Roso e chredeva non poder far cho mancho cha andar ala corte per far mio debyto"), de modo que la noticia del incidente llegó a Venecia tanto por canales oficiales como informales.

El escrito es rico en detalles: para tratar el asunto tuvo que dirigirse a la corte, llegando a destino el 5 de enero de 1404. Aunque no especifica dónde se encontraba, la reconstrucción del itinerario de Enrique III permite afirmar que el cónsul veneciano se dirigió a la villa de Madrid. ${ }^{76}$ El viaje le llevó una decena de días desde Sevilla ("è de quy zornade 10"), por lo que debió partir el 27 de diciembre de 1403. Inmediatamente fue conducido a presencia del monarca, ante quien se lamentó del incidente acaecido en el puerto de Cádiz, y a quien solicitó la restitución de la coca "chon quele parole a my parse fose de bysogno". No sabemos en qué lengua hablaron, pero es probable que el cónsul se expresara en veneciano y el rey en castellano, sin intermediario alguno. Solo así se explica que Venier se haga eco de que el rey sintió mucho el incidente, hasta donde alcanzó a comprender ("per quel chonpresy molte l'ave a mal"). A continuación "la resposta sua fo andase al gardenal, el qual è'l tuto'de sto regno, che luy me darya resposta". Es decir, aunque no se cita su nombre en ningún momento, está claro que el soberano remitió al diplomático a Pedro Fernández de Frías, también citado como Don Pedro de Frías. El obispo de Osma era conocido como "el Cardenal de España", de ahí que la mera referencia al "gardenal" le identifique inmediatamente. Hombre de confianza del antipapa aviñonés Clemente VII, adquirió un gran ascendiente en la corte castellana de Enrique III. Cuando Angelo Venier se entrevistó con él se encontraba en la cima de su poder como consejero del monarca, aunque poco después iniciaría su declive, primero cuando Benedicto XIII le retiró la administración de la diócesis de Osma en junio de 1404, y después cuando perdió el favor del propio soberano en 1405.77

La indicación de dirigirse a Pedro de Frías se hizo siguiendo "suo chostume", es decir, la costumbre castellana. El cardenal "volse veder la comisyò ch 'io aveva da la sygnorya, e questo perché quanto i fano in sto payse tuto fano per ragyon zevil". Aquí Venier muestra una cierta sorpresa ante la ausencia en Castilla de un tribunal específicamente mercantil. Efectivamente, en Venecia había varias magistraturas encargadas de dirimir las disputas de esta naturaleza, de los consoli dei mercanti a la curia dei forestieri (si una de las partes era extranjera) y, por encima de ambas, los Giudici di petizion, con

\footnotetext{
75 Para todas estas cuestiones resulta ineludible remitirse a la excelente monografía de LAZZARINI, Communication and conflict.

76 Veas Arteseros, Itinerario de Enrique III, pp. 122-124.

77 Para su trayectoria vital me remito a Morales MuñIz, "Pedro Fernández de Frías". Para su caída véase Sú́rez Fernández, Castilla, el cisma, pp. 56-57.
} 
múltiples competencias. ${ }^{78}$ Pero en la Castilla de principios del siglo XV no existía equivalente, pues aunque la opinión más extendida entre los comerciantes afirmaba que la justicia ordinaria no era la más apropiada para dirimir los conflictos que surgían en el seno de la universidad de mercaderes, el Consulado de Burgos no se fundó hasta 1494, ya con los Reyes Católicos. ${ }^{79}$

En la Corona castellana los conflictos entre comunidades extranjeras se dirimían ante el tribunal real, o ante quien fuera designado por el monarca a tal efecto, desde el Consejo Real -habitual para los juicios mercantiles y navales con extranjeros-a los corregidores de las ciudades en cuya jurisdicción se hubiera producido el hecho, o jueces nombrados especialmente. ${ }^{80}$ En esta ocasión Enrique III derivó la reclamación formulada por Venier a Pedro de Frías, quien explicó el procedimiento al cónsul veneciano. Lo extraordinario de la cuestión es que, por una vez, encontramos un testimonio de primera mano en el que un representante de una nación afectada pone por escrito el funcionamiento del sistema castellano, con una descripción informal pero altamente explicativa.

El cardenal señaló al diplomático que el problema de su reclamación era de naturaleza procedimental, pues en la praxis civil castellana no bastaba con la comisión oficial del Senado de la república al cónsul, era preceptivo que contara también con la comisión de los damnificados ("iera de bysogno avese comysyon da quey aveva rezevudo el dano"), con un parte de daños detallado. Sin esta última el requerimiento no podía prosperar, porque era preceptiva para obtener otra carta del rey con la que comisionar al Asistente de Sevilla ("de aquistar una letera per nome del re per la qual comese a sto chorezedor de quy"), de modo que inmediatamente intercediera ante los genoveses. Esta indicación tiene sentido porque la sede consular de los ligures estaba establecida en Sevilla, de modo que los cónsules podían proporcionar particulares sobre el asalto sin necesidad de que el Asistente se desplazara a Cádiz, donde había tenido lugar, ni a ningún otro lugar, para recabar informaciones sobre cómo se había desarrollado el ataque, para después elaborar un informe y remitirlo al rey ("el dito comandamento non i diè mai lasar $i$ diti fini el dito chorezedor non vada a Cades e in cadaun altro luogo dove el posa sentir ed aver testimonianze como la cosa pasa del prender de la dita nave, e le dite mandar hordenadamente per schrityra al re"), tras lo cual el monarca tomaría una decisión.

En este punto Angelo Venier no puede avanzar nada más, salvo que, pese a no saber cómo continuaría el proceso, adelanta la buena disposición del rey hacia los venecia-

78 Cassandro, "La curia di petizion"; Muller, The Venetian Money Market, pp. 42-62 y 123-125. Más recientemente resulta obligatoria la consulta de Marrella y Mozzato, Alle origini dell'arbitrato. Para una visión general sobre los tribunales de mercaderes y la justicia mercantil en ámbito itálico y catalanoaragonés nos remitimos a los trabajos contenidos en Tognetti y Maccioni (eds.), Tribunali di mercanti. Sobre el mundo de los mercaderes venecianos sigue siendo indispensable LANE, I mercanti di Venezia.

79 Sobre la carencia en materia de derecho mercantil en la Castilla bajomedieval véase PETIT, Historia del derecho mercantil, pp. 23, 39, 55-58, 127. Para el consulado de Burgos nos remitimos a BALLESTEROS CABallero et al. (dirs.), Actas del V Centenario del Consulado de Burgos. En este punto conviene recordar que la profesora Ogilvie reivindicó hace una década el papel de la justicia ordinaria en materia mercantil en todo el Occidente europeo. Véase OGILvie, Institutions.

80 GonzÁlez ArCe, "El consulado genovés”, p. 182. 
nos, al tiempo que señala que el monarca está muy molesto con los genoveses ("Non so como sequirà, pur sto con bona speranza de aver bona resposta tanto pur quanto sto re par me è ben desposto verso la nostra sygnoria, el contrario verso Zenovesy"). Esta última observación confirma que Enrique III no había cambiado de parecer, pues a mediados de diciembre de 1403, tres semanas antes de la audiencia en Madrid y dos meses antes de la misiva que nos ocupa, el cónsul había remitido otra carta, leída ante el Senado veneciano el 31 de enero de 1404, en la que concebía esperanzas a tenor de la reacción del monarca castellano al conocer el ataque genovés, pues se habría mostrado tajante acerca ante este tipo de comportamientos ("datur nobis bona spes per dictus Rex Castelle nullo modo volet suffere dictam iniuriam"). ${ }^{81}$

El texto de la carta toma en este punto una dirección inesperada. El procedimiento, como ya se ha expuesto, se desvinculó por completo de Castilla y culminó con la sentencia arbitral para dirimir este y otros episodios que enfrentaban a Venecia con Génova, emitida por el conde de Saboya en $1408 .^{82}$ Lo interesante es el análisis que procede a realizar sobre la situación de los genoveses en Castilla y las posibilidades que se abrían para los venecianos. Efectivamente, Venier consideraba que si los mercaderes de la república acudieran con mayor asiduidad a comerciar a Sevilla, el comercio genovés retrocedería ("zerto se da quy se pratichase per nostri puy la marchadantya, de quelo se sta non dubyo pocha remysyon averya verso i diti Zenovesi"). Más aún, lo plantea como una guerra comercial en la que los venecianos tenían el favor del monarca castellano ("questo sostignimento esser molto danoso a Zenovesy che seguramente ly è / una grandysima guera, e questo tal atto aver el re fato in parte per conpia-/-zenzia de la nostra sygnorya, non sequyrya pocho fruto").

En este contexto, llama poderosamente la atención que Angelo Venier considerara la posibilidad de que los genoveses fueran expulsados de Castilla, lo que estimaba como un daño mayor que una guerra naval ("per quanto ho senti e vysto non fo may tenpo de deschazar Zenovesy de sto payse se no ahora, che non posando vegnir in sty paysy non so che maor guera i se podese far non so dove y podese andar zeno y sarya maor guera cha chy armase 40 galye"). La oportunidad la habría propiciado el hartazgo de los castellanos ante la soberbia de la generación de genoveses que frecuentaba Andalucía en el cambio de siglo, al punto de considerar que si los ligures hubieran sido musulmanes que acudían a comerciar, los locales les habrían tratado peor que a los judíos y les habrían expulsado, cosa que no se hacía para no perder el tránsito de mercancías, pues el cónsul veneciano era consciente de que buena parte de las exportaciones castellanas las realizaban los genoveses, motivo por lo que se les ofrecía todo. Sin embargo, en su opinión no quitaba un ápice de razón a los autóctonos ("Prometove tuty castelani sono sy stufy de sta zenerazion per la lor superbya chi se vedese vegny mory a far la marchadantia i sarya tratadi pezo c'a zudye e chazady vya, ma per non perde el trafego de la tera i ofre tuto. Àno gran rasyon").

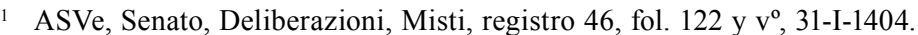

82 Perfectamente analizada en su día por Braunstein, "La capture".
} 
Aunque responsabilizar de la mala relación entre castellanos y genoveses a la soberbia de los ligures probablemente emanara de prejuicios intrínsecos por la propia naturaleza veneciana del cónsul, el malestar de los locales era absolutamente cierto. Su origen, como la percepción de los genoveses como orgullosos, puede situarse en acontecimientos acaecidos una década antes, cuando los patrones castellanos habían intentado obligar a los mercaderes genoveses a usar solo sus navíos en vez de los propios, lo que Enrique III intentó resolver en 1393 decretando que los ligures estaban exentos de la obligación que tenían todos los extranjeros de recurrir preferentemente a la flota castellana en las exportaciones del reino. ${ }^{83}$ Otra muestra fehaciente del apoyo real tuvo lugar en agosto de 1397, cuando las naves genovesas obtuvieron un salvoconducto que las liberaba de la orden de detención para todas las embarcaciones debido al estado de guerra con Portugal. ${ }^{84}$ Los castellanos no debieron acatar de buen grado la exención que permitía a los genoveses emplear sus propias embarcaciones, pues en agosto de 1399 los ligures reiteraron su petición de embarcar mercancías en sus navíos, entre otras cuestiones por la gran cantidad de piratas castellanos que proliferaban, atacando impunemente naves del mismo pabellón, faltas de defensa, con el consiguiente perjuicio para los mercaderes. ${ }^{85}$ Siguiendo con el texto, a continuación contiene un párrafo cuyo contenido no resulta fácil de descifrar. La grafía se vuelve incierta, de lectura complicada, comprometiendo nuestro entendimiento sobre el sentido del escrito. En todo caso, la afirmación de que nunca se había hecho tanto para apoyar a los ligures ("May non i fo fato tanto ato a sostegnyrly") probablemente haya que leerla en la clave del apoyo prestado por Enrique III a los ligures, apenas señalado. La mención de los treinta y cinco que solían ser señores grandes y pequeños de la tierra, que ahora están en un castillo ("soleva eser sygnory / de questa tera pizoly e grandi, tuti stano in uno castelo sono ben 35") es posible que haga referencia a nobles andaluces residentes en la corte, mientras que el castillo podría tratarse de los Reales Alcázares de Sevilla, residencia real en la capital hispalense. Ellos son los que, si los genoveses fueran expulsados, serían los más contrariados y recibirían más daño, tal vez por su relación con los ligures, no solo como abastecedores de artículos de lujo ("Ànno gran despyaser e non pocho danno i schazerà"). En este punto conviene recordar que el éxito económico de algunos miembros de la comunidad conllevó en no pocos casos una mayor relación con las élites locales, entrando a su servicio e incluso, en casos muy destacados, emparentando por matrimonio. ${ }^{86}$

Angelo Venier era consciente de que sus gestiones, aun importantes, no habían obtenido los resultados deseados e incluso parece disculparse por ello ("Ho fato de la mya parte quelo de ben ho posudo"). Su actuación y su obligación se convierten incluso en una cuestión de pundonor ("che per uno venyzian solo abya abudo manyera de sequyr tanto morymento, al vero aveva de gran amistà in lor a hora tute serano perse, non no varda in faza ad omo del mondo se no a far myo debyto") y promete seguir

\footnotetext{
3 González Gallego, "El Libro de los privilegios", doc. XXVIII, 26-II-1393.

4 Ibidem, doc. XXXI, 9-VIII-1397.

85 Ibidem, doc. XXXII, 25-VIII-1399.

86 Para esta cuestión véase GonZÁlez ArÉvalo, “Integración y movilidad social”, pp. 388-377.
} 
trabajando por mejorar las condiciones de sus compatriotas ("da la mia parte sequyrò in proveder a tuto quanto son ublegà").

Entran ahora en consideración acontecimientos internacionales. En Castilla se conocía la sujeción de Génova a Francia porque el propio Carlos VI se lo había comunicado a Enrique III. En su respuesta de marzo de 1397 al rey francés el monarca castellano mostró su satisfacción y prometió que seguiría tratando a los ligures con incluso mayor benevolencia. ${ }^{87} \mathrm{Sin}$ embargo, no es posible determinar hasta qué punto estaban informados en Castilla de los enfrentamientos entre Génova y Venecia, a cuenta de las desastrosas cruzadas franco-genovesas contra los territorios mamelucos desde 1399 por iniciativa del mariscal Jean de Le Meingre, llamado Boucicaut, gobernador francés de Génova. Venecia, a pesar de la petición ligur de no interferir en sus operaciones en 1402, había terminado por advertir al sultán mameluco, lo que enconó más aún las relaciones entre las repúblicas marineras. El enfrentamiento entre ambas había acabado en tablas, aunque con el orgullo de Boucicaut herido por la derrota y captura de tres galeras genovesas en la bocha de Zionclo a manos del famoso Carlo Zeno, el reputado almirante veneciano. ${ }^{88}$ Como se ha señalado previamente, esta última acción estaba en el origen del ataque de las dos cocas genovesas a la coca de Nicolò Rosso en el puerto de Cádiz, que motivó las diligencias de Angelo Venier ante Enrique III a las que se refiere nuestra carta.

Quien sí estaba perfectamente informado sobre el desarrollo de la guerra véneto-genovesa era Angelo Venier. De hecho se muestra contundente al afirmar que la Serenísima no podía fallar ante su rival secular, que tenía todas las esperanzas depositadas en el apoyo del rey de Francia, bajo cuya soberanía se encontraba. Sin él, el cónsul veneciano estaba seguro de la derrota ligur, al tiempo que se hacía eco de las dudas de los genoveses ("la guera tra nuy e Zenovesy non po falir. Tuta la sua speranza à in el re de Franza $e$, manchandoy, prometove vedese la sua desfaziony. Stano in gran dubyo non se acordemo con quey de fora").

Al mismo tiempo, también preveía consecuencias personales, pues con el estado de guerra dudaba de que partieran las galeras de Flandes, las que le habían llevado hasta Andalucía y las que debían devolverle a Venecia, de modo que su estancia se prolongaría forzosamente más de lo que le gustaría ("se guera dyè eser non gredo stano vegna galye per Fyandra. Non vygnendo galye vezome star de quy puy de quelo vorya"). Esta última afirmación deja entrever que, a pesar de las grandes posibilidades que veía en Castilla para el comercio veneciano y de haber realizado hasta el momento todo lo que estaba en su mano para mejorar las condiciones y resarcir daños, Venier no debía

\footnotetext{
87 "Otrosi, muy caro e muy amado hermano, ouve muy grande e apartado plazer de lo que me enviastes dezir que la çiudat de Genua, con todas sus tierras e pertenencias, era vuestra e de vostros succesores e so vuestra obediencia, e como quier que fasta aqui yo gardava los genoveses e los tractava bien en lo que avian de fazer en mis regnos, pero de aqui adelante por vostra onrra e contenplacion yo los avre por mucho encomendados e los gardare e fare por ellos asi como por los mios mesmos en todas las cosas que les fueren menester". SuÁrez Fernández, Castilla, el cisma, p. 206, doc. 41 del apéndice, 9-III-1397. ${ }_{88}$ Un buen resumen reciente del desarrollo de estas hostilidades entre Génova y Venecia, basado fundamentalmente en la lectura de fuentes primarias, en Musarra, Il Grifo e il Leone, pp. 274-280.
} 
estar particularmente cómodo. De hecho, expresa claramente el deseo de regresar a la laguna al finalizar su misión, prevista inicialmente para dos años, como se ha señalado previamente. En este sentido, ya hemos traído a colación la respuesta del Senado a la carta oficial de nuestro cónsul de 16 de febrero, escrita el 10 de abril, comunicándole la llegada inminente de su sustituto, que debía partir para Sevilla ese mismo mes. ${ }^{89}$

No está claro qué ocurrió con posterioridad. Las galeras de Flandes sí partieron ese año, ${ }^{90}$ pero el relevo no llegó a Sevilla y Angelo Venier permaneció en la capital del Guadalquivir al menos hasta que el Senado decidió el cierre del consulado en junio de 1407 y que la comunidad hispalense eligiera un vicecónsul en su lugar ("e conplido che havria ser Anzolo Venere el so tempo, tra i marchadanti se faza un viceconsolo"). ${ }^{91}$ En todo caso, en marzo de 1404 aceptaba con resignación lo que le deparara el futuro y pedía noticias de Venecia ("Hor concludendo Dyo lasy proveder quanto ho dito, zioè al ben de la nostra tera ston con gran desydyeryo de aver letere da Venies per saver como $i$ faty seqyurà").

La última parte de la carta contiene noticias internas de la comunidad veneciana de Sevilla. Así, Venier se hace eco de la presencia en la corte de un cierto Vetor, desplazado desde hacía prácticamente un mes por cuenta de Luca Falier para entregar perlas a un alto noble castellano cuya identidad no se desvela. No sabemos en qué momento había regresado el cónsul de la corte, pero el compatriota había partido antes de su vuelta y no debieron cruzarse por el camino. Es posible que se tratara de personal del consulado -las condiciones de apertura preveían que el cónsul contara con tres famuli para su servicio-, solo así se entiende la afirmación de que si él se hubiera encontrado en Sevilla no habría permitido una marcha que le generaba una evidente inquietud ("Vetor è puy de ziorni 29 non se truova de quy. Syando my a corte, per ser Lucha Falyer fo mandado con perle a uno baron de sta corte. Nonn è anchora vegnudo e sy ne ston con gran dubyo e se fose sta' quy del zerto non n'averya consentydoy lo avese mandado. Pur spero Idyo tornerà con bene").

El motivo de su nerviosismo era el valor de las perlas, que cifraba en mil libras, no tanto porque se las pudieran robar como porque no se fiaba del sujeto, cuyos modos desaprobaba sin disimulo ("non hoservava mody che me pyasese"). Más aún, para incidir en la poca fiabilidad y el poco seso del individuo llega a afirmar que si dispusiera de 30.000 ducados, una cifra fabulosa, se los gastaría en prostitutas ("se l'avese $30^{\mathrm{M}}$ duchati tuti spederya in putane").

El penúltimo párrafo de la carta está dedicado a Luca Falier, de cuya intención de acudir a comerciar a Berbería se hizo eco Angelo Venier en una carta anterior ("Avyseve da prima el dito lucha Falyer pensava anderà in Barbarya"). Como es ampliamente conocido, Sevilla tenía contacto fundamentalmente con el Magreb al-Aqsa, la Berbería

\footnotetext{
89 ASVe, Senato, Deliberazioni, Misti, reg. 46, fol. 127r: "quia de brevi sumus misuri vestrum cambium ad illas partes qui venit ambasiator et consul et est recessurus hinc per totum mensem presentem".

90 El convoy de 1404 estuvo compuesto por cuatro galeras. Cf. Doris Stöckly, Le système..., p. 163.

91 ASVe, Senato, Deliberazioni, Misti, reg. 47, f. 121r.
} 
de Poniente de los documentos italianos. ${ }^{92}$ No extraña pues que la comunidad veneciana de Sevilla comerciara con los productos magrebíes que llegaban al mercado hispalense, sino que también accediera directamente a los mercados del Magreb atlántico, al igual que hacían genoveses y florentinos cuando disponían de embarcaciones propias. Así por ejemplo, en agosto de 1402 el veneciano Simone di Bonafé, a quien hemos visto instalado en Sevilla desde 1400, escribía al director de la filial datiniana en Mallorca, Cristofano di Bartolo Carocci, porque unos corsarios catalanes de Valencia habían capturado a la altura de Sancti Petri, cerca de Cádiz, "uno mio navilio che venia de Barbaria", con un rico botín de 28 libras de cera, 4 libras de melegueta, algodón, lana y cueros berberiscos, de los que más de 400 eran cueros en barriles y entre 60 y 80 cueros desligados. Aparentemente la presa había sido llevada a la isla, motivo por el que le solicitaba que intentara recuperarla. ${ }^{93}$

Más sorprendente aún es una referencia a su vida privada. En el estudio de las comunidades extranjeras presentes en Castilla es muy complicado conocer detalles de este tenor, lo que otorga más valor aún al dato. Efectivamente, Angelo Venier comunica que le han llegado noticias de que Luca Falier ha contraído matrimonio. Nada se sabe de la nueva esposa, pero el hecho de que se refiera a ella de modo casi despectivo y juzgue el casamiento como la mala decisión de alguien que no tiene los pies en el suelo hace pensar que no se habría tratado de un matrimonio ventajoso, tanto menos con una mujer bien posicionada ("Ho sentido a far con una e desposady tanto a dir eser noviza e sapyando non [...] altro ca la testa nonn è in tera"). Más aún, aunque nada se dice sobre su nacionalidad, el volumen reducido de la comunidad veneciana de Sevilla en estos momentos podría ser indicativo de que la mujer no pertenecía a ella, lo que abriría nuevas perspectivas sobre la integración de algunos súbditos de la Serenísima en Andalucía. Comoquiera que sea, el cónsul veneciano no esconde su desaprobación ("de sty fati, àme dado asay despyaser"). Incluso afirma que si fuera su hijo tampoco le daría la razón ("Se'l fose myo fyo, non farya pur a darly hogny cason"). Esta última reflexión, no exenta de paternalismo, podría ser indicativa de una diferencia de edad importante entre ambos, aunque Luca Falier era lo suficientemente adulto como para pensar que sabía bien lo que se hacía ("Non voray per so ben de luy el savese tanto"). En este punto Angelo Venier se despide, pidiendo a los destinatarios que saludaran a la familia más extensa, como hemos referido al principio del análisis de la carta.

\footnotetext{
92 Sobre las relaciones entre la Baja Andalucía y Berbería, incluyendo las mercantiles, mantiene toda su vigencia la síntesis elaborada por LADERo QueSADA, "Castilla, Gibraltar y Berbería”. Desde el punto de vista fiscal, específicamente sobre la renta de Berbería y el papel de Sevilla en ella, véase GoNZÁLEZ ArCE, El negocio fiscal, pp. 71-74.

93 ASPo, Datini, 1076.79 / 424333, Sevilla-Mallorca, 26-VIII-1402. Carta publicada íntegra en HousSAYE Michienzi, Datini, Majorque, p. 331, nota 105. Sobre el mismo incidente escribió también desde la capital hispalense el hermano del director de la filial mallorquina, Giovanni di Bartolo Carocci. Cf. ORLANDI, "A través de la «foce stretta»", pp. 117-118.
} 


\section{Una carta para esclarecer otra carta}

El Archivo General de Simancas conserva una carta del escribano real Bernal González a Enrique III de Castilla, sin año ni lugar de redacción, con informaciones conectadas con el texto que editamos y estudiamos. ${ }^{94}$ Aunque el texto ya ha sido publicado, nuestro análisis permite corregir la fecha adjudicada y arrojar más luz al desarrollo de la presencia veneciana en Andalucía. ${ }^{95}$

A grandes rasgos, la misiva recoge las gestiones realizadas por encargo de Enrique III para adquirir paños de oro y seda y otros artículos que traían las galeras venecianas. Para ello entregó un memorial detallado a Pero Estévanez, que se reunió con Ruy González en Sevilla para que este le pagara la mitad de lo que adquiriera a bordo del convoy. Finalmente, "luego sopimos conmo las dichas galeas eran venidas. E conmo lo sopimos, luego partió de aquí Ruy Gonçáles e Per(o) Estévanes, para yr allá, asý conmo la vuestra merçed ge lo enbió mandar". Aunque no se especifica, resulta indudable que el convoy de Flandes fondeó en Cádiz, la única escala obligatoria en el sur ibérico, ciertamente a una distancia razonable para acudir desde Sevilla y regresar a la capital hispalense en un plazo de tiempo breve. ${ }^{96}$ Bernal González no se desplazó con ellos por encontrarse enfermo ("yo non pude yr allá, por quanto estava flaco"). Una vez a bordo:

estovieron con el capitán dellas, e le fisieron entender el buen amor, e la buena veluntad, que la vuestra alteza avía al común de Venegia, e conmo serían guardados, e defendidos e amparados en esta vuestra terra, e los provechos que dende les podrían venir. E dixo Ruy Gonçáles que les respondiera dando munchas graçias a la vuestra alteza e señoría, en nonbre del duque e común de Venegia, e que de aquí adelante, que vernían seguramente a esta vuestra tierra a faser sus mercaderías.

La invitación realizada a la Serenísima a través del capitán de la muda lleva a pensar dos cuestiones. La primera, que aunque la renovación del tratado con Venecia se remontaba a 1398, los castellanos debían tener la sensación de alguna manera de que realmente no se estaba llevando a efecto. En segundo lugar, el hecho de que se trasladara al capitán veneciano apuntaría que aún no se había abierto el consulado véneto de Sevilla, previsto asimismo en el tratado y cuya puesta en marcha materializó el interés de la república de abrirse camino en un nuevo mercado, Andalucía.

\footnotetext{
94 AGS, Estado, Castilla, leg. 1-1 ${ }^{\circ}$, fol. 153r.

95 Véase García IsaAc e IdÁÑEz Vicente, "Documentos”, doc. XXVI, en la que se especula con 1405 como año de redacción.

96 La anotación de grafía decimonónica en el reverso del documento original, indicando que las galeras estaban surtas en Cartagena -afirmación asumida con dudas en la publicación citada en la nota anteriores completamente errónea. Ningún indicio permite insinuar siquiera que la muda de Flandes hizo escala en el puerto cartagenero ese año.
} 
Respecto al encargo de Enrique III, "díxole Ruy Gonçáles que le fisiese mostrar de los paños de oro, e de seda e de otras joyas, e que él conpraría dellas para sý, e para otros que en su conpañía yvan". Es decir, se ocultó que las adquisiciones eran para el monarca, a buen seguro para evitar un incremento abusivo en los precios. Sin embargo, se pudo constatar que "non avía cosa alguna de lo que la vuestra merçed enbía mandar, por vuestro memorial, que conprásemos, ni aún de los axaropes e espeçias, sy non bien poco". El capitán había ordenado traer de las otras galeras a la presencia de los visitantes "todos los paños que en ellas avía, disiendo que non avía más, que en Málaga avían vendido todo lo más que traýan, toda la plata e paños". También explicó que "non traýan las dichas galeas agora las cosas que solían, por el grand daño que avía fecho el Taborlán en terra de Suria, donde solian venir todas estas buenas joyas". Una aclaración que resulta clave para datar el texto.

Timur Lang, el 'Tamorlán' de Ruy González de Clavijo, fundador del último gran imperio mongol en Asia Central, conquistó Damasco en el invierno de 1400-1401. ${ }^{97}$ La muda de Beirut había partido el 29 de agosto de 1400 y regresó a Venecia el 5 de enero de $1401 .^{98}$ La república estaba puntualmente informada del desarrollo de los acontecimientos porque muchos mercaderes y representantes de la república en localidades como Alepo - conquistada en otoño de 1400 - o la propia Damasco huyeron a Chipre. ${ }^{99}$ En consecuencia, los venecianos eran perfectamente conscientes de las dificultades para seguir desarrollando el comercio en la región, de modo que se decidió no enviar el convoy de 1401. A pesar de la marcha posterior del emperador mongol, los encantes de 1402 para el viaje de Siria revelan una gran reticencia aún para retomar los contactos mercantiles con la zona, lo que explica que solo se enviaran dos galeras frente a las siete de 1400, y que el encante de la muda de Alejandría se disparara. ${ }^{100}$

La muda de Flandes recaló en el puerto gaditano de camino al mar del Norte. En este punto no hay margen para la duda, pues previamente se habían vendido en Málaga todos los paños y la plata que llevaban. Respecto a la fecha, la carta está redactada en Sevilla el 26 de junio, cuando Ruy González había informado a Bernal González de que las galeras "partieron luego ese día dende". Mediado junio, al final de la primavera, es una fecha que cuadra con los tiempos de navegación necesarios para alcanzar la Bahía de Cádiz, pues a partir de 1401 se decidió que las galeras de esa línea partieran entre finales de marzo y abril. ${ }^{101}$

Con toda probabilidad se trataba de la flota que partió al año siguiente, en 1402. Lo corroborarían varios datos: como acabamos de ver, en 1401 no zarpó la flota con destino a Beirut, lo que interrumpió el flujo de los artículos importados desde Siria, como había explicado el capitán del convoy, y el intercambio en el que Venecia actuaba como intermediaria en Occidente. La muda de Beirut de 1402, que reanudó a duras penas el

\footnotetext{
Fischel, "A New Latin".

8 STÖCKLY, Le système, p. 151.

99 Ahstor, Levant Trade, pp. 112-114.

100 STÖCKLY, Le système, pp. 147-148.

101 Ibidem, p. 161.
} 
comercio veneciano, debió partir ese verano, más de cinco meses después de que lo hiciera la de Flandes, regresando a la laguna en enero de 1403. Para mayor confirmación, en 1403 no zarparon las galeras de Flandes. ${ }^{102}$

La flota veneciana de 1402 con destino al mar del Norte era la encargada de llevar a Angelo Venier, el primer cónsul veneciano de Sevilla, hasta el punto más cercano a su destino: Cádiz. ${ }^{103}$ Y más aún, pues las galeras iban cargadas con

los paños, e otras cosas que venían para se vender en esta çibdat, que los traýa un mercader veneçiano, que aý venía con él, que llaman Johan, hermano de Luca; el qual Luca, estava aquí en Sevilla, e fue con Ruy Gonçáles e con Pero Estévan(es) a las dichas galeas

Aunque no se incluye el patronímico de los venecianos, cabe albergar pocas dudas de que se trata de Luca y Giovannino Falier, lo que confirmaría la posibilidad aludida más arriba de que eran hermanos. Y lo que es más importante aún: una vez establecida la fecha más probable de la carta en 1402, podemos plantear nuevas cuestiones. Para empezar, que Luca Falier estaba en Sevilla antes de la apertura del consulado véneto. De hecho, debía llevar ya un tiempo arraigado en Castilla, el suficiente cuanto menos para poder introducirse en la corte y llegar hasta el monarca en persona. Así lo confirmarían varias cuestiones. De entrada, que se desplazó desde Sevilla hasta Cádiz con los oficiales regios, a los que acompañó en su visita a las galeras. Además, de vuelta en la capital hispalense, los representantes reales le compraron cendales y tres paños. Y no solo: aunque fuera buscando sacar mayor provecho, estos últimos dieron a entender a Giovannino que no lograría vender el resto en el mercado sevillano, presumiblemente por su alto coste, pero ellos los comprarían para el rey "sy quisiese faser dellos preçio raçonable". El veneciano se excusó ("dixo que lo non podía faser"), pero "a cabo de tres días que esto pasó, dixo que quería enbiar los dichos paños con su hermano Luca a la vuestra merçed. E por ser más seguro, que fuese con él Pero Estévanes, vuestro criado". E decir, parece claro que Giovannino llevaba la voz cantante en los negocios familiares, decidiendo él qué se vendía y a quién, actuando Luca como factor suyo, tal vez en una sociedad familiar más amplia, con sede en Venecia. Y en dicha calidad, Giovannino comunicaba a los oficiales regios la intención de enviar los paños al rey y solicitaba la protección de su criado en el trayecto.

En la corte Luca Falier trataría directamente con Enrique III, lo que da idea de la consideración que se le tenía en la corte castellana ("el preçio de los dichos paños el dicho Luca lo fará ante la vuestra merçed"), mientras Giovannino permanecía en Sevilla "porquel mercader espera otros paños que tiene en Arlés". Esta última información revela negocios en Provenza. Probablemente recurriría a la navegación privada para el transporte desde el Ródano hasta el Guadalquivir, pues la Serenísima no puso en

\footnotetext{
102 Ibidem, p. 163.

103 ASVe, Senato, Deliberazioni, Misti, reg. 46, fol. 4r, 7-III-1402.
} 
marcha la muda de Aigües Mortes, que alcanzaba la ruta de las galeras de Flandes en la Corona de Aragón, hasta 1402-1403. ${ }^{104}$

En este contexto cabe pensar que los hermanos Falier -cuanto menos Luca, establecido previamente en Sevilla- con toda probabilidad tuvieron un papel significativo en la apertura del consulado veneciano. Por lo demás, ya hemos señalado que Luca Falier se mantuvo activo en la capital hispalense hasta 1413 como máximo. Por su parte, Giovannino Falier es uno de los perjudicados por el ataque genovés a la coca de Nicolò Rosso. La reclamación posterior le sitúa en Cádiz aún diciembre de 1403, un año y medio después de haber llegado a Andalucía con la muda de Flandes.

\section{Conclusiones}

El estudio de la parábola vital de individuos concretos es una herramienta muy útil para arrojar luz a la situación interna y el desarrollo de comunidades concretas a través del método prosopográfico. En esta ocasión, un hecho bien conocido y ya analizado en el pasado - la captura de la coca de Nicolò Rosso en el puerto de Cádiz en diciembre de 1403- es el punto de partida que generó una abundante documentación. Aunque en sus rasgos generales fue excelentemente trabajada por Philippe Braunstein, una relectura desde la perspectiva concreta de los intereses venecianos en Andalucía arroja nuevos matices. En este punto ha resultado fundamental reconstruir la identidad y la vida de nuestros protagonistas para entender el alcance de su vinculación temporal con el territorio, lo que ha encontrado enormes dificultades por la escasez y la dispersión de las informaciones.

Al mismo tiempo, queda clara la necesidad de prestar más atención al papel desempeñado por la navegación privada veneciana en aguas ibéricas, una actuación que ha quedado ensombrecida por la atención recibida por las galeras mercantiles de la república, merced a su mayor visibilidad y a un volumen de documentación ingente en comparación. De cualquier modo, todos los datos que emergen invitan constantemente a una nueva evaluación en este sentido. Cada vez resulta más evidente su papel en el comercio y la navegación entre el Mediterráneo y el Atlántico, más allá de la cuenca mediterránea occidental, y también en trayectos de corto y medio radio, sin conexión obligatoria con la laguna, incluyendo el contacto desde Andalucía con el Magreb atlántico, un itinerario habitual entre los naturales de la tierra, también practicado en menor medida por las comunidades extranjeras, principalmente la genovesa, pero igualmente la florentina y, como se confirma ahora, la veneciana.

No cabe duda de que el hallazgo de una carta enviada por el primer cónsul de la Serenísima en Andalucía es un descubrimiento importante, especialmente por las dificultades que entraña el estudio de la nación en el territorio. La categoría extraordinaria del documento se confirma por la riqueza de detalles que incluye, empezando por la

\footnotetext{
104 Para el papel de la muda de Aigües Mortes en el Mediterráneo ibérico me remito a GonzÁlez Arévalo, “Acordes y desacuerdos", pp. 162-164 y 185.
} 
explicación del procedimiento civil seguido en Castilla para dirimir conflictos entre naciones extranjeras en su territorio, un testimonio de primer orden.

En segundo lugar, no es habitual encontrar una impresión tan detallada -por más que esté contaminada por la propia naturaleza del autor- sobre la percepción y la convivencia con los genoveses en el territorio andaluz. De nuevo, se confirman las dificultades derivadas de una posición de privilegio absoluto, aun a costa de los intereses de mercaderes y patrones castellanos. En este sentido, no cabe duda de que la política de los reyes de Castilla difería bastante de la desarrollada en otros territorios ibéricos, particularmente en la Corona de Aragón, por esos mismos años. ${ }^{105}$ Bien es cierto que la corona catalano-aragonesa competía directamente con los venecianos, como con las demás naciones mercantiles italianas, tanto en el Mediterráneo oriental (Egipto mameluco) como en el Magreb central, si bien en la cuenca occidental los principales rivales eran los genoveses. ${ }^{106} \mathrm{Al}$ mismo tiempo, en el trasfondo de las impresiones vertidas por Angelo Venier subyace el secular conflicto veneciano-genovés, que tuvo precisamente uno de sus últimos episodios en la primera década del siglo XV, y en el ataque a la coca de Nicolò Rosso en el puerto de Cádiz uno de sus episodios más llamativos y mejor conocidos.

En tercer lugar, el carácter informal de la comunicación permite espacio para consideraciones de tipo personal, tanto del propio cónsul, que expresa su deseo de regresar a Venecia tras dos años en Castilla, como sobre otros miembros de la comunidad veneciana presente en Andalucía, en particular Luca Falier, al que se refiere con expresiones absolutamente familiares para reprobar su reciente matrimonio.

Por último, el esclarecimiento del entorno humano que figura en la carta en última instancia ha llevado a arrojar más luz sobre otro documento fundamental para el conocimiento de las actividades venecianas en Castilla y su contacto directo con la élite política y social a principios del siglo $\mathrm{XV}$, empezando por el propio soberano.

En definitiva, la puesta en valor del documento, cuya edición se ofrece por primera vez, así como el cruce de informaciones con otras fuentes, oficiales y privadas, supone una aportación más en el complicado mosaico, siempre incompleto, de la presencia extranjera, italiana en general y veneciana en particular, en la Andalucía bajomedieval.

\section{Apéndice ${ }^{107}$}

ASVe, Procuratori di S. Marco, Misti, Commissarie, b. 85a, fasc. VI, lettera Siviglia Venezia. 15 de febrero de 1403 [more veneto]

\footnotetext{
105 Congdon, "Venetian and Aragonese/Catalan Relations".

106 Para el comercio veneciano en los sultanatos mameluco y hafsí nos remitimos a las obras de AHSTOR, Levant Trade, y Doumerc, Venise. Para el comercio catalán en esos mismos espacios véase Coulon, Barcelone, y López Pérez, La Corona de Aragón.

107 Transcripción de Tommaso Vidal.
} 
Carta del cónsul veneciano en Sevilla, Angelo Venier, informando sobre las gestiones realizadas en la corte castellana para recuperar la mercancías y la coca de Nicolò Rosso, capturada en el puerto de Cádiz por dos cocas genovesas. Se añaden impresiones sobre la situación de los genoveses en Andalucía y en el conflicto que les enfrenta a la Serenísima. Asimismo, se incluyen informaciones privadas y comerciales de otros miembros de la comunidad véneta.

//Fol. 1r//

\section{Per M barba M C}

Al nome de Dio amen 1403 in Sybilya

A miser e simel de padre. Per puy sue mie hove avisy quanto a me parso del bysogno, / e puy ve avysy de la presa de ser Nicholo Roso e chredeva non poder far cho man-/-cho cha andar ala corte per far mio debyto. Hor per questy como a padre avyserove quanto ho sentì per eser andà dal re.

Ziunsy a dì 5 zener dove iera la corte, ed è de quy zornade 10, honde sub-/-ito zionto fu a la presenzia del re, agrevandome de quel ne iera sta' fato in / suo portto / chon quele parole a my parse fose de bysogno a resituzion del / nostro, el qual per quel chonpresy molte l'ave a mal. La resposta sua fo / andase al gardenal, el qual è'l tuto' de sto regno, che luy me darya / resposta. E per che el non mi parvy da nuovo el dito re fese tal respo-/-sta dygo ch'è senpre suo chostume e de al dar tuto e posa de cho-/-meter el delyvrar ad alter. Fu puy, frade, a parlamento chon el dito / gardenal, non manchando per mi in quel che cognosyti, ly disse tute rasion / iera de bysogno pe far che l'aver de' Zanovesy de qui fosemo satisfati del nostro. / Stado puy ziorni su questo volse veder la comisyò ch'io aveva da la sygno-/-rya, e questo perché quanto $\mathrm{i}$ fano in sto payse tuto fano per ragyon zevil. / La qual vista luy respose non i pareva per quela avese pyena lybertà, di-/-gando iera de bysogno avese comysyon da quey aveva rezevudo el dano, hon-/-de ben che a questa parte i respondese quelo mi parese puy fese suo / fondamento digando iera de bysogno avese la dita comysyon, non dy men pur / àvy maniera de aquistar una letera per nome del re per la qual / comese a sto chorezedor de quy che subito, vista la dita, intrometese / Zenovesy in aver. E inperonne subito mostradomi la dita manda a sechu-/-zion el dito comandamento non i diè mai lasar i diti fini el dito chore-/-zedor non vada a Cades e in cadaun altro luogo dove el posa / sentir ed aver testimonianze como la cosa pasa del prender de la dita / nave, e le dite mandar hordenadamente per schrityra al re el qual / termenerà poy viste le dite quanto el dito corezedor dye scryver, / sy de dyti Zenovesi como del suo aver. Non so como sequirà, pur sto / con bona speranza de aver bona resposta tanto pur quanto sto re / par me è ben desposto verso la nostra sygnoria, el contrario verso Zeno-/-vesy, che zerto se da quy se pratichase per nostri puy la marchadantya, de / quelo se sta non dubyo pocha remysyon averya verso i diti Zenovesi. E l'è zi-/-à chosy serti del suo 
aver zià se simo sta' satisfati, honde concludendo respeto / questo sostignimento esser molto danoso a Zenovesy che seguramente ly è / una grandysima guera, e questo tal atto aver el re fato in parte per conpia-/-zenzia de la nostra sygnorya, non sequyrya pocho fruto la sygnorya manda-/-se qual che solena anbasya, che per quanto ho sentì e vysto non fo may / tenpo de deschazar Zenovesy de sto payse se no ahora, che non posando / vegnir in sty paysy non so che maor guera i se podese far non so dove y po-/-dese andar zeno y sarya maor guera cha chy armase 40 galye.

//Fol. 1v//

Prometove tuty castelani sono sy stufy de sta zenerazion per la lor superbya chi se ve-/-dese vegny mory a far la marchadantia i sarya tratadi pezo c'a zudye e cha-/zady vya, ma per non perde el trafego de la tera i ofre tuto. Ànno gran rasyon. / May non i fo fato tanto ato a sostegnyrly in aver, e inperonne soleva eser sygnory / de questa tera pizoly e grandi, tuti stano in uno castelo sono ben 35. Ànno / gran despyaser e non pocho danno i schazerà. Che hocora quelo se vorà, var-/gerà puy d'uno mese avanti i posa eser delyvrade ben pode conprender pui / stato solo quanto dano i retornerà./

Ho fato de la mya parte quelo de ben ho posudo, pur my pyase l'andadi nonn è / stato indarno che non n'abya seguydo qualche cosa. Zerto sto ato solo non / n'è stà pocho non $[\ldots]^{108}$ che per uno venyzian solo abya abudo manyera / de sequyr tanto morymento, al vero aveva de gran amistà in lor a hora tute / serano perse, non no varda in faza ad omo del mondo se no a far myo debyto / e sequyr verso de lor quelo son zerto vorya seqyse verso de nu. Dyo / per sua gratia lasy sequy ch'el nostro ne sya restituydo, my da la mia parte sequyrò / in proveder a tuto quanto son ublegà./

Àme parso a non n'aver posudo far con mancho ch'aver fato a saver per meso / propryo a la sygnorya, pur non dubyo serà sta' contenta abia mandando sto meso / ho puy sue letere che la guera tra nuy e Zenovesy non po falir. Tuta la sua spe-/-ranza à in el re de Franza e, manchandoy, prometove vedese la sua desfa-/-ziony. Stano in gran dubyo non se acordemo con quey de fora e se / guera dyè eser non gredo stano vegna galye per Fyandra. Non vygnendo / galye vezome star de quy puy de quelo vorya. Hor concludendo Dyo / lasy proveder quanto ho dito, zioè al ben de la nostra tera ston con gran desydyeryo / de aver letere da Venies per saver como i faty seqyurà./

Vetor è puy de ziorni 29 non se truova de quy. Syando my a corte, per ser Lucha / Falyer fo mandado con perle a uno baron de sta corte. Nonn è anchora ve-/-gnudo e sy ne ston con gran dubyo e se fose sta' quy del zerto non n'averya / consentydoy lo avese mandado. Pur spero Idyo tornerà con bene. Àno per-/-le per valore de $\mathrm{lb} \mathrm{M}$ e zionto fu de quy sentì non hoservava mody che / me pyasese e quanto or voyo dir è 'l vero el'avyzy, gran briega será / a ritrarlo se l'avese $30^{\mathrm{M}}$ duchati tuti spederya in putane. Dyo i dya / gratia e'l faza bone che anchora per mi non mancherà non i ne dya hon-/-ni bona casyon./

$\overline{108 \text { Lectura incierta. }}$ 
Avyseve da prima el dito Lucha Falyer pensava anderà in Barbarya / e sy el menerya con meso che porya eser sta' casyon de so gran / ben. Dubito per quelo l'à senty de da novo non el voya menar, ma pur $/[\ldots]^{109}$ posa far lo'l mena. Ho sentido a far con una e desposady tanto a dir / eser noviza e sapyando non $[\ldots]^{110}$ altro ca la testa nonn è in tera. / Idyo el lasy capitar ben pur de sty fati, àme dado asay despyaser / quanto ho dito. Se'l fose myo fyo, non farya pur a darly hogny cason el sye / qua ben ${ }^{111}$ zerto e'l sa asay $[\ldots]^{112}$ zerto per tegnerse saver ${ }^{113}$ quelo el / sa i schavaza e'l cola. Non voray per so ben de luy el savese tanto.

//Fol. 2r//

Usando in mody lasa e so ben ne avere' despyaser, e pensa che non vel $/[\ldots]^{114}$ volentyery casyon me'l fa schryver./

Né altro per questa my resta, salvo my pyaqua rechomandarme a mya aniedre / e a miser Piero Pisyani, Crestyna e i garzony, priegove ne sya rechomandadi. / Dyo vegese my e amyo conpare nostro frar ho ... a luy el [...] a myo con-/-mare.

Per Anziolo Vener symel

de fyo vy se rechomanda clusa a dì 15 fevrer.

//Fol. 2v//

Egregy e potenty my-/-lyti domino Gabryely Ay-/-mo, honorbile Zany / Venyziarum dette.

[monograma de Angelo Venier]

In Venyes [alia manu] die primo avril.

\section{Bibliografía}

Ashtor, Eliyahu, Levant Trade in the Latter Middle Ages, Princeton University Press, Princeton, 1983.

Balard, Michel, "La lotta contro Genova", en Girolamo Arnaldi, Giorgio Cracco y Alberto Tenenti (eds.), Storia di Venezia. Dalle origini alla caduta della Serenissima. Vol. 3. La formazione dello stato patrizio, Istituto della Enciclopedia Italiana, Roma, 1997, pp. 87-126.

Ballesteros Caballero, Floriano et al. (dirs.), Actas del V Centenario del Consulado de Burgos (1494-1994), Diputación Provincial de Burgos, Burgos, 1994.

\footnotetext{
${ }_{109}$ Lectura incierta.

110 Lectura incierta.

111 Ben añadido entre líneas.

112 Lectura incierta.

113 Después de saver sigue asay tachado.

114 Lectura incierta.
} 
Braunstein, Philippe, "La capture d'une coque vénetienne sur la route de Flandre au début du XV' siècle", en Henri Dubois, Jean-Claude Hocquet, André Vauchez (coords.), Horizons marins, itinéraires spirituels ( $V^{\mathrm{e}}-X V I I I^{\mathrm{e}}$ siècle). Volume II. Marins, navires et affaires, Éditions de la Sorbonne, Paris, 1987, pp. 111-122.

Cassandro, Giovanni, "La curia di petizion", Archivio veneto, XIX (1936), pp. 72-144, y XX (1937), pp. 1-210.

Cogdon, Eleanor A., "Datini and Venice: News from the Mediterranean Trade Network", en Dionisius A. Agius, Ian Richard Netton (eds.), Across the Mediterranean Frontiers. Trade, Politics and Religion, 650-1450, Brepols, Turnhout, 1997, pp. 157-171.

Cogdon, Eleanor A., "Private Venetian ships and shipping c. 1400", Al-Masaq, 10 (1998), pp. 57-71.

Congdon, Eleanor A., "Venetian and Aragonese/Catalan Relations: Protectionist Legislation in 1398-1404", Medieval Encounters, 9/2-3 (2003), pp. 214-235.

Coulon, Damien, Barcelone et le grand commerce d'Orient au moyen âge. Une siècle des relations avec l'Egypte et la Syrie-Palestine (ca. 1330-ca. 1430), Casa de Velázquez, Madrid, 2004.

Corazzol, Gigi (ed.), Dispacci di Zaccaria Barbaro. 1 novembre 1471 - 7 settembre 1473, Istituto Poligrafico e Zecca dello Stato, Roma, 1994.

Doumerc, Bernard, Venise et l'émirat hafside de Tunis (1231-1535), L'Harmattan, París, 1999.

FÁBregas García, Adela, "Estrategias del los mercaderes toscanos y genoveses en el reino de Granada a través de la correspondencia Datini", Serta Antiqua et Medievalia, V (2001), pp. 259-304.

FÁBregas GarcíA, Adela, "Acercamientos y acuerdos comerciales entre Granada y Venecia al filo de 1400”, Anuario de Estudios Medievales, 40/2 (2010), pp. 643-664.

FIschel, Walter J., “A New Latin Source on Tamerlane's Conquest of Damascus (1400/1401). (B. Mignatelli's "Vita Tamerlani" 1416). Translated into English with an Introduction and a Commentary", Oriens, 9/2 (1956), pp. 201-232.

FuEss, Albrecht, "Why Venice, not Genoa: How Venice Emerged as the Mamluks' Favourite European Trading Partner after 1365", en Georg Christ, Franz-Julius Morche, Roberto ZAugG, Wolfgang Kaiser, Stefan Burkhardt y Alexander D. Beihammer (eds.), Union in Separation. Diascporic Groups and Identities in the Eastern Mediterranean (1100-1800), Viella, Roma, 2015, pp. 251-266.

García IsAac, José Marcos, e IdÁÑEz Vicente, Carmen, "Documentos para la historia de Cartagena durante el reinado de Enrique III de Castilla”, Historia Digital, 18 (2018), pp. 160-199.

GonzÁlez Arce, José Damián, "El consulado genovés de Sevilla (siglos XIII-XV)", Stvdia Historica. Historia medieval, 28 (2010), pp. 179-206. 
GonzÁlez Arce, José Damián, El negocio fiscal en la Sevilla del siglo XV. El almojarifazgo mayor y las compañias de arrendatarios, Diputación de Sevilla, Sevilla, 2017. GonzÁlez Arévalo, Raúl, "Presencia diferencial italiana en el sur de la Península Ibérica en la Baja Edad Media. Estado de la cuestión y propuestas de investigación", Medievalismo, 23 (2013), pp. 175-208.

GonzÁlez Arévalo, Raúl, "Florentinos entre Cádiz y Sevilla en los siglos XIV y XV", en Eduardo Aznar Vallejo y Roberto J. González Zalacaín (coords.), De mar a mar. Los puertos castellanos en la Edad Media, Universidad de La Laguna, La Laguna, 2015, pp. 273-308.

GonZÁlez ArÉvalo, Raúl, "Vecinos y propietarios: La integración de los italianos en las sociedades portuarias andaluzas (siglos XIII-XV)”, en Jesús Ángel Solórzano Telechea, Beatriz Arízaga Bolumburu y Michel Bochaca (eds.), Las sociedades portuarias de la Europa atlántica en la Edad Media, Instituto de Estudios Riojanos, Logroño, 2016, pp. 249-284.

GonZÁlez ArÉvalo, Raúl, "Integración y movilidad social de los italianos en la Corona de Castilla: genoveses, florentinos y venecianos en la Andalucía bajomedieval", en Lorenzo Tanzini y Sergio Tognetti (eds.), Competenze, conoscenze e mobilità sociale nell'Italia del basso Medioevo, Viella, Roma, 2016, pp. 375-401.

GonZÁlez ArÉvalo, Raúl, “Acordes y desacuerdos. Navegación y comercio de las galeras mercantiles de Venecia y Florencia en el Mediterráneo ibérico desde una perspectiva comparada", en Raúl González Arévalo (ed.), Navegación institucional y navegación privada, Granada, Alhulia, 2016, pp. 145-191.

GonzÁlez ArÉvalo, Raúl, "Galeras y mercaderes venecianos en el Reino de Granada. Nuevas aportaciones desde las fuentes vénetas (siglo XV)”, Mainakke, XXXVI (2016), pp. 247-262.

GonzÁlez Arévalo, Raúl, "Del Guadalquivir al Nilo. El testamento de Andrea de Razi (1477) y la comunidad veneciana de Sevilla a finales del siglo XV", Nuova Rivista Storica, CIII/2 (2019), pp. 417-450.

GonzÁlez ArÉvalo, Raúl, "De la laguna al océano: la presencia veneciana en el Golfo de Cádiz (siglo XV)”, Suplemento de Riparia, 2 (2019), pp. 113-141.

GonzÁlez Arévalo, Raúl, “Del Adriático al Atlántico: Venecia y Cádiz entre navegación, diplomacia y comercio (siglos XIV-XV)”, Hispania, 80/264 (2020), pp. 11-45.

GonzÁlez Arévalo, Raúl, "Cum necessarium sit habere consulem nostrum in Sibilia. El consulado veneciano de Sevilla (1402-1407)", en Daniel Baloup y Benoît Joudiou (eds.), Une mer pour les réunir tous. Études sur la Méditerranée offertes à Bernard Doumerc ( $I X^{\mathrm{e}}-X V I I^{\mathrm{e}}$ siècle), Toulouse, Presses Universitaires du Midi, en prensa.

GonzÁlez Arévalo, Raúl, "En el Rio di Sibilia. Sanlúcar de Barrameda, puerto subsidiario del comercio italiano entre el Mediterráneo y el Atlántico (siglos XIV y XV)", en Juan Leonardo Soler Milla (ed.), Puertos, tráfico mercantil y comercio marítimo (ss. $X I I-X V)$. Nuevas perspectivas de investigación, en prensa. 
GonzÁlez Gallego, Isidoro, "El Libro de los privilegios de la nación genovesa”, Historia. Instituciones. Documentos, 1 (1974), pp. 275-358.

Hocquet, Jean-Claude, Il sale e la fortuna di Venezia, Jouvence, Roma, 1990.

Houssaye Michienzi, Ingrid, Datini, Majorque et le Maghreb (14 $-15^{\mathrm{e}}$ siècle), Brill, Leiden-Boston, 2013.

Il Codice Morosini. Il mondo visto da Venezia (1094-1433). Tomo primo. Introduzine e Cronaca-Diario dal 1094 al 1413 (fino a tutto il dogato di Michele Steno), a cura di Andrea Nanetti, Centro Italiano di Studi sull'Alto Medioevo, Spoleto, 2010.

Ladero Quesada, Miguel Ángel, “Castilla, Gibraltar y Berbería (1252-1516)”, en Miguel Ángel Ladero Quesada, Los Mudéjares de Castilla y otros estudios de historia medieval andaluza, Universidad de Granada, Granada, 1989, pp. 169-219.

Lane, Frederic C., I mercanti di Venezia, Einaudi, Turín, 1982.

LAZZARINI, Isabella, Communication and conflict. Italian Diplomacy in the Early Renaissance, 1350-1520, , Oxford University Press, Oxford, 2015.

LeVantino, Laura (ed.), Venezia - Senato, Deliberazioni miste, Registro XXIX (13591361), Istituto Veneto di Scienze, Lettere ed Arti, Venecia, 2012.

Libri commemoriali della Repubblica di Venezia. Regesti, R. Deputazione Veneta di Storia Patria, tomo III, vol. VII, Venecia 1883.

LóPEz PÉRez, María Dolores, La Corona de Aragón y el Magreb en el siglo XIV (13311410), CSIC, Barcelona, 1995.

LÓPEZ de Coca CASTAÑER, José Enrique, "Las galeras venecianas de Poniente y Berbería desde la perspectiva española”, Medievalismo, 16 (2006), pp. 113-172.

Mariutti de SÁnchez Rivero, Ángela, "Da Veniexia per andar a meser San Zacomo de Galizia per la uia de Chioza", Príncipe de Viana, 108-109 (1967), pp. 441-514.

Marrella, Frabrizio y Mozzato, Andrea, Alle origini dell'arbitrato commerciale internazionale. L'arbritrato a Venezia tra Medioevo ed età moderna, con prefacio de Andrea Giardina, CEDAM, Padua, 2001.

Melero Fernández, M. Inés, "Fondos medievales del Archivio di Stato de Venecia referentes a los reinos españoles. Regestos", Miscellania de Textos Medievals, 5 (1989), pp. 329-359.

Miller, Edward y Hatcher, John, Medieval England: Towns, Commerce and Crafts, 1086-1348, Londres-Nueva York, Routeledge, 1995.

Montemezzo, Stefania (ed.), Giovanni Foscari. Viaggi di Fiandra. 1463-1464 e 14671468, La Malcontenta, Venezia, 2012.

Morales MuñIz, Dolores Carmen, "Pedro Fernández de Frías”, Diccionario biográfico español, Real Academia de la Historia, voz online: http://dbe.rah.es/biografias/15705/ pedro-fernandez-de-frias [última consulta: 10 de enero de 2021]. 
Muller, Reinhold C., The Venetian Money Market. Banks, Panics and the Public Debt, 1200-1500, The Johns Hopkins University Press, Londres, 1997.

Musarra, Antonio, Il Grifo e il Leone. Genova e Venezia in lotta per il Mediterraneo, Laterza, Bari-Roma, 2020.

OgILvie, Sheilagh, Institutions and European Trade. Merchant Guilds, 1000-1800, Cambridge University Press, Cambridge, 2011.

Orlandi Angela, “Ibiza entre el Mediteráneo, el Atlántico y el Mar del Norte (siglos XIV y XV), eHumanista, 38 (2018), pp. 48-64.

OrLANDI, Angela, “A través de la «foce stretta». De Sevilla a Valencia y no solamente (1382-1411)", Nuova Rivista Storica, 103/1, 2019, pp. 109-141.

Orlando, Ermanno (ed.), Venezia - Senato, Deliberazioni miste, Registro XXVIII (13571359), Istituto Veneto di Scienze, Lettere ed Arti, Venecia, 2009.

PAsi, Bartolomeo, Tariffa de’ Pesi e mesure correspondenti dal Levante al Ponente, Venezia, 1521.

Petit, Carlos, Historia del derecho mercantil, Marcial Pons, Madrid, 2016.

SтӧскLY, Doris, Le système de l'Incanto des galées du marché à Venise, fin XIIle - milieu XVe siècle, Brill, Leiden-Nueva York-Colonia, 1995.

SuÁRez Fernández, Luis, Castilla, el cisma y la crisis conciliar (1378-1440), CSIC, Madrid, 1960.

Surdich, Francesco, Genova e Venezia fra Tre e Quattrocento, Fratelli Bozzi, Genova, 1970.

Tognetti, Sergio, “Galeras estatales y veleros privados en la República florentina del Cuatrocientos: la praxis mercantil”, en Raúl González Arévalo (ed.), Navegación institucional y navegación privada en el Mediterráneo medieval, Alhulia, Granada, 2016, pp. 105-144.

Tognetti, Sergio y Maccioni, Elena (eds.), Tribunali di mercanti e giustizia mercantile nel tardo medioevo, Olschki, Florencia, 2016.

Veas Arteseros, Francisco de Asís, Itinerario de Enrique III, Universidad de Murcia, Murcia, 2003. 